\title{
FUTURISTIC MODEL OF ELECTRIC VEHICLE CHARGING QUEUES
}

\author{
by \\ HesAm AKBARI \\ BEng, Ryerson University, Toronto, Ontario, Canada 2013
}

\author{
A Thesis \\ presented to Ryerson University \\ in partial fulfillment of the \\ requirements for the degree of \\ Master of Applied Science \\ in the Program of \\ Electrical and Computer Engineering
}

Toronto, Ontario, Canada, 2015

(C)Hesam Akbari 2015 
I hereby declare that I am the sole author of this thesis. This is a true copy of the thesis, including any required final revisions, as accepted by my examiners.

I authorize Ryerson University to lend this thesis to other institutions or individuals for the purpose of scholarly research.

I further authorize Ryerson University to reproduce this thesis by photocopying or by other means, in total or in part, at the request of other institutions or individuals for the purpose of scholarly research.

I understand that my thesis may be made electronically available to the public. 


\title{
Futuristic Computer Model of Electric Vehicles Charging Queues
}

Master of Applied Science 2015

\author{
Hesam Akbari \\ Electrical and Computer Engineering \\ Ryerson University
}

\begin{abstract}
The use of PEVs (Plug-in Electric Vehicles) is fast expanding due to their low energy cost and low environmental pollution. However, a big hurdle is that PEVs have a short driving range and long battery charging time even when using supercharging stations. Therefore, better queuing models are necessary to improve the quality of services using public charging stations. This thesis develops an approach for estimating various discharging profiles of PEV batteries considering different regional driving cycles. Each driving cycle generates a unique discharging profile. These discharging profiles were employed in a computer model to study recharging process of PEVs in public charging stations. Moreover, a unique utility function is construed which is optimized to minimize the overall waiting time for consumers and harmonize the queue size in each charging station. This model uses Toronto downtown area as a case study.
\end{abstract}




\section{Acknowledgements}

I would like to express my sincere thanks to my supervisor, Professors Xavier Fernando, for giving me the opportunity to explore this subject and make the most of my graduate studies. I am extremely thankful and indebted to him for sharing expertise, valuable guidance and encouragement extended to me throughout this study.

Special thanks to Ryerson University, Ryerson Communication Lab (RCL), and Hydro One for support and funding this research work. 


\section{Dedication}

This Master's Thesis is dedicated to my family specially my mother Mehsati who have supported me since the beginning of my study. 


\section{Table of Contents}

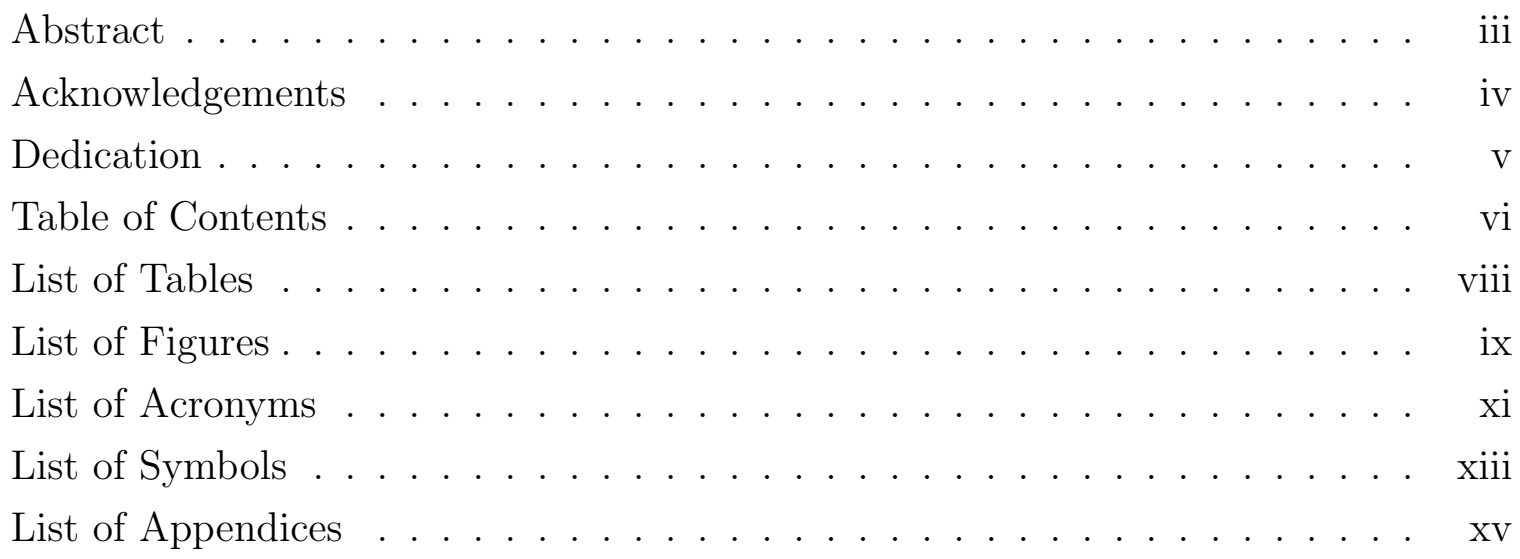

1 Introduction $\quad 1$

1.1 PEVs' Effect on Electrical Grid . . . . . . . . . . . . . . . . . . . . 2

1.2 Coordinated Control System Strategies . . . . . . . . . . . . . . . . 3

1.3 Problem Statement . . . . . . . . . . . . . . . . . 4

1.4 Thesis Organization . . . . . . . . . . . . . . . . . . . 5

2 Background and Previous Research Works $\quad 7$

2.1 Battery Modeling . . . . . . . . . . . . . . 8

2.1.1 Basic Terms of Battery Performance and Characterization . . . . 8

2.1.2 Equivalent Circuit Models of Battery . . . . . . . . . . . . . . . . 11

2.2 Electric Vehicle Battery Technologies . . . . . . . . . . . . . . . 15

2.2.1 Li-ion Batteries . . . . . . . . . . . . . . . . . . . 17

2.3 Schematics of Possible PHEV Architectures . . . . . . . . . . . . . 20

2.3.1 Series PHEV Architecture . . . . . . . . . . . . . . 20

2.3.2 Parallel PHEV Architecture . . . . . . . . . . . . . . . . 22

2.3.3 Power-Split PHEV Architecture . . . . . . . . . . . . . . 23

2.4 PHEV Battery Discharging Concept . . . . . . . . . . . . . . . . . . . . 24 
3 Driving Cycles and State of Charge Analysis 26

3.1 Introduction . . . . . . . . . . . . . . . . . . . . 26

3.2 Driving Cycles . . . . . . . . . . . . . . . . . . . . . . . . 27

3.2.1 U.S. Environmental Protection Agency (EPA) . . . . . . . . 28

3.3 Plug-in Electrical Vehicle Model . . . . . . . . . . . . . . . . . . . . . . 32

3.3.1 Vehicle and Battery Model Simulation . . . . . . . . . . . 32

$3.3 .2 \quad$ Logic Mode . . . . . . . . . . . . . . . . . . . . . . . . 33

3.4 Results and Post Processing . . . . . . . . . . . . . . . 36

$3.4 .1 \quad$ FTP-72 Post Analysis . . . . . . . . . . . . . . 37

$3.4 .2 \quad$ HWFET Post Analysis . . . . . . . . . . . . . . . 38

$3.4 .3 \quad$ SC03 Post Analysis . . . . . . . . . . . . . . . . . 40

3.4.4 US06 Post Analysis . . . . . . . . . . . . . . . . . . . . . . . 41

3.5 Conclusion and Discussion . . . . . . . . . . . . . . . . . . 43

4 PEV-Station Interaction and Driving Algorithm 45

4.1 Queueing Model and Station Framework . . . . . . . . . . . . . 46

$4.1 .1 \mathrm{M} / \mathrm{M} / 1$ Queueing Model . . . . . . . . . . . . . . . 47

4.2 Modeling PEVs and Charging Stations . . . . . . . . . . . . . 49

4.3 Utility Function . . . . . . . . . . . . . . . . . . . . . . . . . 52

4.4 Selected Case Studies . . . . . . . . . . . . . . . . . . . . . . . 54

5 Practical Application and Analysis $\quad 58$

5.1 Mapping and Station Locations _. . . . . . . . . . . . . . . 59

5.1 .1 City of Toronto's Map . . . . . . . . . . . . . . . 59

5.1.2 Modeling PEVs and Charging Stations in Toronto . . . . . . . 61

5.2 Sensitivity Analysis . . . . . . . . . . . . . . . . . . . . . 63

5.3 Location Allocation . . . . . . . . . . . . . . . . . . . . . 67

6 Conclusions and Future Work $\quad 73$

$\begin{array}{ll}\text { Appendices } & 75\end{array}$

$\begin{array}{ll}\text { A Parameters of Electric Vehicle Model } & 76\end{array}$

$\begin{array}{lr}\text { References } & 80\end{array}$ 


\section{List of Tables}

2.1 Batteries used in electric vehicles of selected car manufacturers. . . . . 16

3.1 FTP-72 driving cycle electrical consumption results. . . . . . . . . . . 37

3.2 HWFET driving cycle electrical consumption results. . . . . . . . . . 39

3.3 SC03 driving cycle electrical consumption results. . . . . . . . . . . . 40

3.4 US06 driving cycle electrical consumption results. . . . . . . . . . . . . 42

3.5 EPA tested driving cycles results. . . . . . . . . . . . . . . . . 44

4.1 Variability of each station queue size for each case study. . . . . . . . 55

4.2 Minimum variability of each station queue size in each case. . . . . . . 55

5.1 Grid and geographical area of selected downtown Toronto coordinates. . . 61 


\section{List of Figures}

2.1 Fundamental electrical circuit models of battery. . . . . . . . . . . . . . 14

2.2 Charging profile of a Li-ion battery cell. . . . . . . . . . . . . . . . 18

2.3 Discharging profile of a Lead acid battery cell. . . . . . . . . . . . . . . 19

2.4 Fundamental of PHEV architecture. . . . . . . . . . . . . . . . . . . . . . 21

2.5 Power-split PHEV architecture. . . . . . . . . . . . . . . . . . . . . . 21

2.6 Different stage of SOC behavior in PHEVs. . . . . . . . . . . . . . . . 24

3.1 The U.S. FTP-72 simulated driving cycle, length of 1369 seconds, average speed of $31.5 \mathrm{~km} / \mathrm{h}, 18$ total stops, and distance of $12.07 \mathrm{~km}$. . . . . . . . 29

3.2 The U.S. HWFET simulated driving cycle, length of 765 seconds, average speed of $77.73 \mathrm{~km} / \mathrm{h}$, and distance of $16.51 \mathrm{~km} . \quad$. . . . . . . . . . . . 29

3.3 SC03 speed correction driving schedule, length of 596 seconds, average

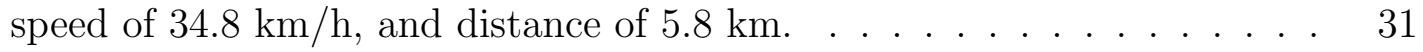

3.4 US06 or supplemental FTP driving schedule, length of 596 seconds, average speed of $77.4 \mathrm{~km} / \mathrm{h}$, and distance of $12.8 \mathrm{~km}$. . . . . . . . . . . . . 31

3.5 Simulated configuration of PHEV block parameter including control logics, electrical system level, power split device, vehicle dynamics, and mechanical engine block. . . . . . . . . . . . . . . . . . . . . . . . 34

3.6 Customized battery with 10 battery cells for PHEV model. . . . . . . . . 35

3.7 Mode logic specification flow chart for PHEV . . . . . . . . . . . . . 36

3.8 Discharging profile of Electric Vehicle battery obtained using FTP-72 driving cycle standard. . . . . . . . . . . . . . . . . . . . 38

3.9 Discharging profile of electric vehicle battery obtained using HWFET driving cycle standard. . . . . . . . . . . . . . . . . . . . 39

3.10 Discharging profile of electric vehicle battery obtained using SC03 driving cycle standard. . . . . . . . . . . . . . . . . . . . . . . . . . . 41 
3.11 Discharging profile of electric vehicle battery obtained using US06 driving cycle standard. . . . . . . . . . . . . . . . . . . . . . . 42

4.1 Multi-station framework with multiple $M / M / 1$ queue system. . . . . . . 46

$4.2 M / M / 1$ queue structure and analysis. . . . . . . . . . . . . . . . . . 48

4.3 Proposed 2-D system with $x$ interval [0, 1000] and $y$ interval [0, 1000]. 100 PEVs and 9 stations are existed in this platform. PEVs initial location is selected randomly.

4.4 A PEV driving and mode pattern for one day. Charging station is selected based on closest distance between the PEV and stations. solid line $(\operatorname{mode}=0)$ indicates the driving pattern of the vehicle and plus sign indicates driving patern of the vehicle when SOC is critical (mode=1). . 51

4.5 PHEV charging and driving flowchart algorithm in one day. . . . . . . . 53

4.6 Queue size behavior of all 9 stations for all 3 tested cases. . . . . . . . . . 57

5.1 Down town Toronto simulated map. . . . . . . . . . . . . . . . . . . . . . 60

5.2 Overall load distribution of 23 charging stations queue in down-town Toronto for one day when all sensitivity parameters and coefficients are one. . . .

5.3 Km driven for all $100 \mathrm{PEVs}$ in down-town Toronto with average drive of $45.05 \mathrm{~km}$ for each vehicle when all sensitivity parameters and coefficients set to one(23 stations).

5.4 Overall load distribution of 23 charging stations queue in down-town Toronto for one day when all sensitivity coefficients was optimized. . . . . . . . 66

5.5 Km driven for all $100 \mathrm{PEVs}$ in down-town Toronto with average drive of $48.22 \mathrm{~km}$ for each vehicle when all sensitivity coefficients was optimized(23 stations). . . . . . . . . . . . . . . . . .

5.6 PEVs location of first critical SOC (red) and existing charging stations location (black) in downtown Toronto. . . . . . . . . . . . . . . . .

5.7 Applied Minkowoski and Chebyshev distance method results to allocate new facility location. . . . . . . . . . . . . . . . . . 71

5.8 Overall load distribution of 24 charging stations queue in down-town Toronto for one day when all sensitivity coefficients was optimized. . . . . . . . . 72

5.9 Km driven for all $100 \mathrm{PEVs}$ in down-town Toronto with average drive of $42.03 \mathrm{~km}$ for each vehicle when all sensitivity coefficients was optimized (24 stations). 


\section{List of Acronyms}

$\begin{array}{ll}\text { AWD } & \text { All Wheel Drive } \\ \text { BMS } & \text { Battery Management System } \\ \text { CD } & \text { Charge Depleting } \\ \text { CFR } & \text { Code of Federal Regulations } \\ \text { CS } & \text { Charge Sustaining } \\ \text { DOD } & \text { Depth of Discharge } \\ \text { DSM } & \text { Demand Side Management } \\ \text { EG } & \text { Electrical Grid } \\ \text { EPA } & \text { Environmental Protection Agency } \\ \text { EV } & \text { Electrical Vehicle } \\ \text { FTP-72 } & \text { Federal Test Procedure 72 } \\ \text { GMDC } & \text { General Map Data Center } \\ \text { HEV } & \text { Hybrid Electrical Vehicle } \\ \text { HWFET } & \text { Highway Fuel Economy Test } \\ \text { ICE } & \text { Internal Combustion Engine } \\ \text { Li-ion } & \text { Lithium-ion battery } \\ \text { MDP } & \text { Markov Decision Process } \\ \text { NiMH } & \text { Nickelmetal hydride battery } \\ \text { NREL } & \text { Natural Renewable Energy Laboratory } \\ \text { PDMs } & \text { Property Data Maps } \\ \text { PEV } & \text { Plug-in Electrical Vehicle } \\ \text { PHEV } & \text { Plug-in Hybrid Electrical Vehicle } \\ \text { QoS } & \text { Quality of Services } \\ \text { RPM } & \text { Revolutions Per Minute } \\ \text { SAE } & \text { Society of Automotive Engineers } \\ & \end{array}$


SG Smart Grid

SOC State of Charge

$\mathrm{SOH} \quad$ State of Health

STP Standard Temperature and Pressure 


\section{List of Symbols}

$\alpha \quad$ Data center sensitivity parameter for distance between vehicle and stations

$\beta \quad$ Data center sensitivity parameter for queue size of stations

$\lambda \quad$ Arriving rate per hour

$\lambda_{i} \quad$ PHEV arrival rate per hour for station $i$

$\mu \quad$ Service rate per hour

$\mu_{i} \quad$ PHEV service rate per hour for station $i$

$\rho \quad$ Utilization quantity of queue

a Customer sensitivity coefficient to distance between vehicle and stations

$b \quad$ Customer sensitivity coefficient to queue size of each stations

$C_{1} \quad$ Overvoltage capacitance

$C_{b} \quad$ Battery capacitance

$C_{b} \quad$ Storage capacitance

$C_{c} \quad$ Charging/discharging capacitance

$\left(c_{i}, d_{i}\right) \quad$ Coordinate of existing station $i$

$C_{T} \quad$ Equivalent heat capacitance $\left(\mathrm{J} / C^{\circ}\right)$

$D_{i j} \quad$ Distance between vehicle $j$ and station $i$

$\left(e_{i}, f_{i}\right)$ Coordinate of Initial critical SOC location of vehicle $i$

$E\left[N_{i}\right] \quad$ Mean queue size of station $i$.

$i \quad$ Terminal current (A)

$i_{b} \quad$ Current through capacitor $C_{b}(\mathrm{~A})$

$i_{c} \quad$ Current through capacitor $C_{c}(\mathrm{~A})$

$L \quad$ Average number of people in queueing system

$L_{q} \quad$ Average people in queue

$L_{s} \quad$ Average people in server

$N(t) \quad$ Number of customers arriving during a time interval $(0, t]$ 


$\begin{array}{ll}q_{a c} & \text { Air conditioning force heat transfer rate }(\mathrm{W}) \\ q_{b} & \text { Heat transfer rate generated by the battery cell(W) } \\ q_{c} & \text { Conducting heat transfer }(\mathrm{W}) \\ Q_{i j} & \text { Queue size of station } i \text { when vehicle } j \text { need to be charged } \\ R_{1 c} & \text { Overvoltage resistance for charge } \\ R_{1 d} & \text { Overvoltage resistance for discharge } \\ R_{2 c} & \text { Interval resistance for charge } \\ R_{2 d} & \text { Interval resistance for discharge } \\ R_{b} & \text { Resistance for storage capacity } \\ R_{c} & \text { Resistance for charging/discharging capacity } \\ R_{p} & \text { Self-discharge resistance or insulation resistance } \\ R_{T} & \text { Equivalent thermal resistance }\left(C^{\circ} / \mathrm{W}\right) \\ T_{a} & \text { Air temperature }\left(C^{\circ}\right) \\ T & \text { Cell temperature }\left(C^{\circ}\right) \\ v & \text { Terminal voltage }(\mathrm{V}) \\ v_{b} & \text { Voltage of capacitor } C_{b}(\mathrm{~V}) \\ v_{c} & \text { Voltage of capacitor } C_{c}(\mathrm{~V}) \\ W & \text { Average waiting time spend in queuing system } \\ w_{i} & \text { Weight associate with travel between new facility and existing facility } i \\ W_{q} & \text { Average time each vehicle spend in queue } \\ W_{s} & \text { Average time each vehicle spend in server } \\ x_{i j} & \text { Normalized distance between vehicle } j \text { and station } i \\ (x, y) & \text { Coordinate of new facility } \\ y_{i j} & \text { Normalized queue size of station } i \text { when vehicle } j \text { need to be charged } \\ \end{array}$




\section{List of Appendices}

Appendix List of all the simulation parameters used to simulate PHEV. 


\section{Chapter 1}

\section{Introduction}

Plug-in Electric Vehicles (PEVs) are the new generation of vehicles. These vehicles are progressively expanding due to their low energy cost and low pollution. Electrical Grid (EG) connectivity is one of the significant features of PEVs. Nowadays, the amount of electricity is produced by renewable and green energy sources helps PEVs consume the clean energy, which leads to lower emissions. Moreover, consumers may also save money by using PEVs due to the high cost of fossil fuel. Hence, PEVs are becoming more common in the market and have become a reliable form of transportation. Statistics indicates that the number of PEV consumers has experienced an annual increase of $80 \%$

since 2000 [1]. In fact, it is estimated that by the end of $2015,10 \%$ of all new vehicles sold will be PEVs [2]. 


\subsection{PEVs' Effect on Electrical Grid}

In addition to all the advantages, a number of facts have to be taken into consideration.

Despite the potential benefits for PEV owners when compared to conventional vehicles, reconciliation will be needed between vehicle owners and grid operators [3]. In general, increase in system's peak load, increase in losses, decrease in voltage and system load factor are impacts of PEVs on the electrical grid. There is a natural coincidence between peak electricity demand and vehicles returning to their residence after a daily commute. This coincidence between vehicle charging demand and existing peak demand is a concern from the utility point of view. Previous studies have called for some form of control over vehicle charging to avoid adding to the peak demand $[4,5]$. The existing solution is to coordinate charging process of PEVs based on the relationship between feeder losses, load factor, and load variance to minimize impacts (system losses) and improve voltage regulation.

Traditionally, the power grid refers to an interconnected transmission power system using analog technology. However, the term Smart Grid (SG) is a nebulous term spanning various functionalities geared towards modernizing the power grid. At its core, a smart grid utilizes digital communications and control systems to monitor and control power flows, with the goal of making the power grid more resilient, efficient and cost

effective [6]. Coordinated charging can help to reduce the pressure on EG in compari- 
son with uncoordinated charging. However, it also compromises the Quality of Services (QoS) since the consumers have minimum control over this process.

\subsection{Coordinated Control System Strategies}

By using electric power, PEVs can alleviate the energy crisis and shift the energy demand from the transportation sector to the power system. The widespread deployment of PEVs in near future is like a double-edged sword for the power grid [7]. This fact, may increase the peak load on the power grid and cause power quality problem. Need for a control system is inevitable for PEVs charging process to reduce voltage and frequency deviation caused by electric vehicles. However, deployment of PEV technologies have a various number of uncertainties and variables in real-world. Uncertainties such as PEVs early departure error (i.e., the PEV departs prior to the expected departure time), and load prediction errors continue to fail intelligent control methods. Therefore, economic benefits are usually traded for robustness of the system [8]. Markov Decision Process (MDP) have been used to model uncertainties in control systems based on the change in real-time electricity price and, customer's uncertainty behavior in Demand Side Management(DSM) $[9,10]$. A real-world scenario of business model is also needed besides the robust control strategies. The centralized control system is complicated to implement in the real world as it may sacrifice the benefits of certain customers for achieving a 
better payoff in the whole system [7]. There are many proposed decentralized control systems that has been studied and applied. The noncooperative game model for PEVs to participate in frequency regulation [11] and, applied game theory to integrate PEVs as demand-side resources for DSM in the building energy control [12] are examples of such studies.

\subsection{Problem Statement}

Even though the coordinated system seems to be the solution for PEVs charging process, it compromises the QoS to consumers. In this case, PEV owners have minimum control over charging process of their vehicle which is unsatisfactory. Customer's uncertainty behavior also has a significant role in developing a feasible control strategy. A proper system modeling is required to define a middle ground to minimize the overall system load and PEVs' charging time. Studying PEV's charging/discharging process beside applying control strategy, helps to achieve this objective. A coordinated balance system also is a key to harmonizing load on the power system and improve PEV consumers charging experience.

The aim of this research is to investigate the SOC behavior of PEV considering different driving cycles that lead to an estimation of PEV's need of charging in different scenarios. Study of the discharging behavior of PEVs leads to investigate how vehicle im- 
plement load to the charging stations in the absence of vehicle charging control strategies. In fact, behavior of consumers has a high impact on the charging process performance.

This thesis proposes an efficient operational framework for multiple charging stations, which offers a harmonized system and improved overall charging experience for consumers. The customer behavior affects not only the overall charging process time but also the queue size and the load on the charging stations. The objective is to introduce a simple and suggestive system for optimizing PEVs' charging process to improve PEVs' overall charging time. Moreover, queue balance of stations is another aspect of this investigation. Our system is a computer model simulation, which allows the real-time information delivery to PEVs or smartphone applications either based on 3G network or internet $[13,14]$.

\subsection{Thesis Organization}

Chapter 2 of this thesis contains literature review, where existing battery models, existing PEV (PHEV and EV) battery technologies and architectures are explored. The literature review highlights the fact that PEV batteries are different that the regular batteries due to their high power capability and configuration. Also, they have different discharging behavior and profile due to numerous conditions.

In Chapter 3, a model of PEVs is simulated with different existing driving cycle 
standards to investigate the discharging behavior of PEVs under different circumstances. Based on captured data, a proper discharging curve was modeled over time for each scenario.

Following this, Chapter 4 investigates and proposes a queueing model of stations as well as driving algorithm of PEVs. The driving algorithm considers discharging profile of PEVs battery and their critical battery state. A Proper framework was developed to test the driving algorithm and PEVs interaction with stations. Moreover, a utility function was proposed based on a relationship between the distance of each vehicle to each station and charging station queue size.

Chapter 5, starts with the impact of PEV charging on existing stations in downtown Toronto and how the utility function can be improved through sensitivity analysis to harmonize and balance the overall stations queuing size. Sensitivity analysis aims to investigate the consumer's decision making based on preference on shortest distance or smaller queue size of each station. A new facility location was also suggested considering the location of initial critical charge of PEVs and existing charging stations. In the discussion and conclusion section of Chapters 6, the key results and insights are highlighted followed by recommendations for future work. 


\section{Chapter 2}

\section{Background and Previous Research}

\section{Works}

A proper understanding of battery helps to investigate PEVs and how they interact with charger and charging stations. PHEVs and EVs are using different battery technologies compared to hybrid vehicles due to their higher energy and energy density. A comprehensive study of equivalent battery circuits along with charging and discharging behavior of batteries helps to develop a realistic model for PEVs. Each type and architecture of PEVs has different effects on battery size, vehicle capability and discharging rate of their battery. Therefore, review of existing PEVs architectures is essential for modeling a proper discharging profile in different scenarios. 


\subsection{Battery Modeling}

Battery modeling is an essential tool for improving battery design, manufacturing, and control of EV's and PHEV's battery packs. Also, it's a standard procedure to estimate the correct State of Charge (SOC) and State of Health ( $\mathrm{SOH}$ ) of the batteries. Extensive research has been carried out on battery modeling. Researchers developed a variety of models for various aspects and purposes [15].

\subsubsection{Basic Terms of Battery Performance and Characteriza- tion}

Before any further investigation, the terminologies of the battery and battery performance have to be explored for deeper understanding. The terms define the characteristic and behavior of the battery that lead to improvement of battery models. Following are the useful terms of battery performance:

Ampere-hour Capacity: Ampere-hour (Ah) is the possible total charge that can discharge from a fully charged battery under standard condition. The rated Amperehour defines the maximum capacity of a fully charged battery under predefined condition performed by its manufacturer. This condition includes temperature, discharging rate, etc. An alternative term defining the capacity of the battery is Watt-hour (Wh). This name is popular with regular consumers. The rated Wh 
capacity is represented by the following equation:

$$
\text { Rated Wh Capacity }=\text { Rated Ah Capacity } \times \text { Rated Battery Voltage. }
$$

C-rate : The term C-rate or C (nominal C-rate) is used to present a charge or discharge rate equal to the capacity of a battery in one hour [16]. In the late $1700 \mathrm{~s}$, CharlesAugustin de Coulomb ruled that a battery that receives a charge current of one ampere (1A) passes one coulomb (1C) of charge every second. That means, in 10 seconds, 10 coulombs pass into the battery, and so on. On discharge, the process reverses. Today, the battery industry uses C-rate to scale the charge and discharge current of a battery [16].

State of Charge (SOC): The most popular term in existing battery industry. SOC defines the remaining capacity of the battery that is affected by its operating conditions such as load current, temperature, etc. In other words, SOC is simply the relation between remaining capacity of the battery and maximum capacity.

$$
\mathrm{SOC}=\frac{\text { Remaining Capacity }}{\text { Rated Capacity }}
$$

Moreover, SOC can be express in terms of Ah capacity as it is stated in (2.3). In battery management, SOC is a critical condition due to challenges in accurate SOC 
evaluation even though it is the key to the operational performance of batteries. Therefore, a proper study is required to understand and model SOC in different conditions and situations. The changes in SOC is defined as follow:

$$
\Delta \mathrm{SOC}=\operatorname{SOC}(\mathrm{t})-\operatorname{SOC}\left(t_{o}\right)=\frac{1}{\text { Ah Capacity }} \int_{t o}^{t} i(\tau) d \tau
$$

Cut-off Voltage : Cut-off voltage is the minimum allowable voltage that is defined by the manufacturer. This term interpreted by industry as the "empty" state of battery $[17]$.

Depth of Discharging (DOD): DOD definition is the total percentage of battery that has been discharged. DOD value can reach to $80 \%$ or higher in deep-cycle batteries.

$$
\mathrm{DOD}=1-\mathrm{SOC} .
$$

State of Health (SOH): $\mathrm{SOH}$ is the ratio of the maximum charge capacity of an aged battery to the maximum charge capacity when the battery was new [18]. SOH is an important parameter that indicates the quality of performance of batteries for estimating battery's remaining lifetime as it is defined as follow:

$$
\mathrm{SOH}=\frac{\text { Aged Energy Capacity }}{\text { Rated Energy Capacity }}
$$


Cycle Life: Cycle life is the maximum number of charging and discharging cycles a battery can handle at $80 \%$ DOD before it fails desired specific performance criteria. The higher the DOD, the shorter the life cycle is [17]. Therefore, to achieve higher life cycle, lower DOD is required during normal operations batteries, especially in large batteries.

Battery Management System (BMS): Battery management system is a management unit which is designed to decide the maximum charging or discharging current and duration from estimated SOC and $\mathrm{SOH}$ of the battery packs. BMS unit is a hardware unit including sensors, controller, communication and hardware with software algorithms [17].

\subsubsection{Equivalent Circuit Models of Battery}

There are two general models classified as electrochemical models and equivalent circuit models for batteries. For the purpose of this research, the electrical equivalent circuit models are considered. Electric circuits models are lumped-parameters that are developed based on comprehensive simulation studies. For studies of system integration, control, optimization and even inter-connectivity of EVs and PHEVs to the grid, a lumped parameter is required [17]. The battery as a lumped load defines battery terminals and overall characteristic and dynamics such as voltage, current, temperature, 
and SOC. These models are also used in various simulation software such as PSpice and MULTISM. Moreover, algebraic or differential equations model of battery are useful in simulation environment such as MATLAB and Simulink along existing generic battery models in Simpower subsystems.

According to various fundamental electrical circuit literature, batteries can be characterized as an ideal voltage source. There are two standard models in electrical systems as they are indicated in Figure 2.1. These models along their popularity, cannot characterize SOC or thermodynamics due to their simplicity. First model in Figure 2.1(a) indicates the mathematical model for battery equivalent circuit [19]. Diodes in this circuit are ideal, and they are used to identify the charging and discharging path in battery along with relevant resistance for each action. $C_{b}$ and $R_{p}$ indicate battery capacity and self-discharge resistance (insulation resistance) respectively on the left side of the circuit. $R_{2 c}$ and $R_{2 d}$ are internal resistance for charging and discharging. Also, over-voltage resistance and capacitance for charge and discharge are represented by $R_{1 c}, R_{1 d}$ and $C_{1}$. According to actual electrochemical reactions and temperature dependent, the values of these capacitors and resistors are definable [19]. The second model is developed by Natural Renewable Energy Laboratory in Figure 2.1(b). This electrical circuit model for the battery is part of ADVISOR tool package which is indicated as a RC network [20]. This model consists of resistors $\left(R_{b}, R_{c}, R\right)$ and capacitors $\left(C_{b}, C_{c}\right)$. $C_{b}$ denotes storage 
capacity and $C_{c}$ denotes fast charging/discharging aspect of the battery. $C_{b}$ is much larger than $C_{c}$ since it represent storage capacity of the battery. Terminal voltage and current of battery is defined by $v$ and $i$ respectively. $C_{b}$ 's voltage and current are $v_{b}$ and $i_{b}$. Also, $C_{c}$ 's capacitor voltage and current denote as $v_{c}$ and $i_{c}$. Following relations were obtained by applying basic circuit analysis to NREL battery model.

$$
\begin{aligned}
& C_{b} \dot{v}_{b}=-i_{b} \\
& C_{c} \dot{v}_{c}=-i_{c} \\
& v_{b}-i_{b} R_{b}=v_{c}-i_{c} R_{c} \\
& i=i_{b}+i_{c} \\
& v=v_{c}-i_{c} R_{c}-i R .
\end{aligned}
$$

The thermal model of the battery is not a part of equivalent battery circuits. Therefore, thermal model may be represented by a lumped first order equation with linear dynamics in (2.7). The parameters of the components are functions of SOC and battery temperature. $T$ denotes cell temperate and $T_{a}$ represents air temperature in ${ }^{\circ} C . R_{T}$ is the thermal resistance $\left(C^{\circ} / \mathrm{W}\right)$ which depends on whether the battery is in "charge" or "discharge" mode. Also, $C_{T}$ is equivalent heat capacitance in $\left(\mathrm{J} / C^{\circ}\right) \cdot q_{b}$ is heat transfer rate generated by the battery cell, $q_{c}$ is thermal conduction and $q_{a c}$ is air conditioning forced heat. The relation between these parameters come as followed: 


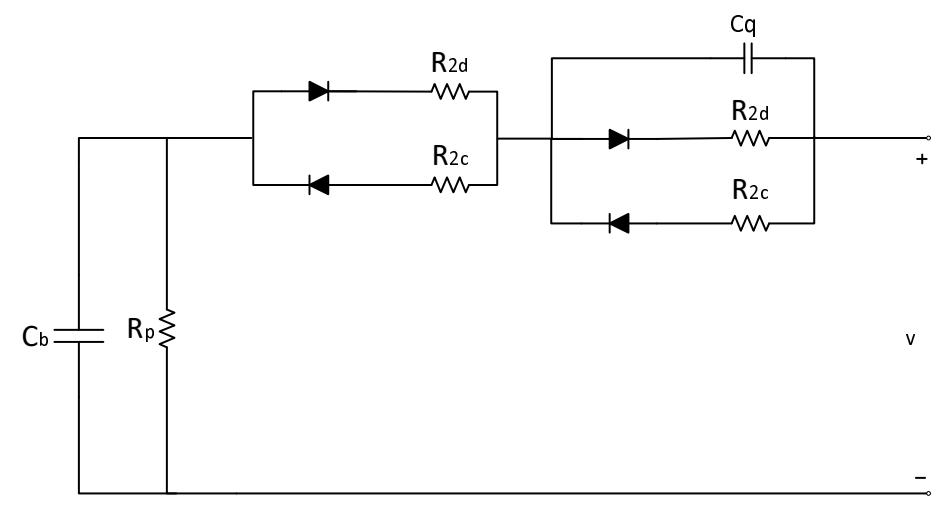

(a) Equivalent circuit model battery reported [19]

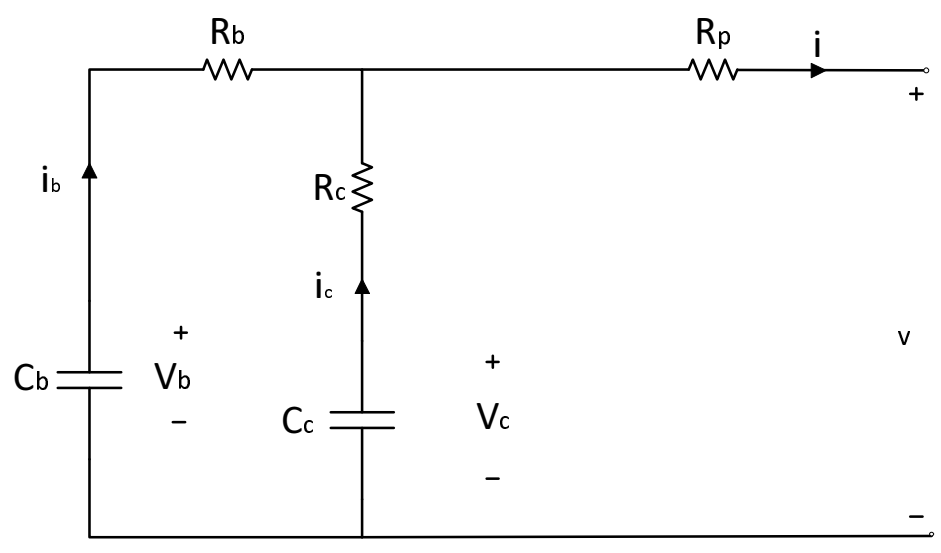

(b) NREL battery model [20]

Figure 2.1: Fundamental electrical circuit models of battery. 


$$
\begin{aligned}
& q_{c}=\left(T-T_{a}\right) / R_{T} \\
& C_{T} \dot{T}=q_{b}-q_{c}-q_{a c} .
\end{aligned}
$$

Considering (2.6) and (2.7), total SOC can be defined as a combination of SOC in $C_{b}$ and $C_{c}$ considering the battery temperature. In (2.8), $S O C_{b}$ and $S O C_{c}$ are functions of $v_{b}$ and $v_{c}$ respectively while the sum of variables $\alpha_{b}$ and $\alpha_{b}$ is one. For instant, in described NREL model $\alpha_{b}$ is set to $20 / 21$ and $\alpha_{c}$ is equal to $1 / 21$ [20]

$$
S O C=\alpha_{b} S O C_{b}+\alpha_{c} S O C_{c}
$$

\subsection{Electric Vehicle Battery Technologies}

Electrical vehicle batteries are moderately different in comparison with existing batteries in the market (regular laptop, cell phones and other consumer electronic devices). In fact, EV and PHEV batteries are designed to handle high power with rated value of 100 kWh. They also have high energy capacity within a limited space and weight while they have to be affordable in price.

U.S and Canadian governments are strongly supporting the R\&D activities towards advancement of these batteries through the department of energy (DOE). For instance, 2 billion dollars grants are dedicated to accelerating the manufacturing and development 
of the next generation of U.S batteries and EVs in 2011 [21]. Only two different types of battery technology are used in manufactured vehicles according to Table 2.1 [22]. HEVs mostly use NiMH due to its mature technology. On the other hand, Lithium ion (Li-ion) is being used in EVs and PHEVs due to its potential for obtaining higher specific energy and energy density. Therefore, EVs and PHEVs can integrate into futuristic power grids (Smart and Micro Grid), and can be used for grid support such as renewable accommodation, frequency regulation, voltage profile regulation and system optimization [22]. For the purpose of this research, Li-ion battery technology is studied more comprehensively.

Table 2.1: Batteries used in electric vehicles of selected car manufacturers.

\begin{tabular}{|c|c|c|c|}
\hline Company & Country & Vehicle Model & Battery Technology \\
\hline \hline GM & USA & Chevy-Volt & Li-ion \\
\hline Ford & USA & Saturn Vue Hybrid & NiMH \\
& & Escape, Fusion, MKZ HEV & NiMH \\
& & Escape PHEV & NiMH \\
\hline Toyota & Japan & Prius, Lexus & NiMH \\
\hline Honda & Japan & Civic, Insight & Lithium polymer \\
\hline Hyundai & South Korea & Sonata & Li-ion \\
\hline Chrysler & USA & Chrysler 200C EV & Li-ion \\
\hline BMW & Germany & X6 & Li-ion \\
& & Mini E $(2012)$ & NiMH \\
\hline BYD & China & E6 6 & Li-ion \\
\hline Daimler Benz & Germany & ML450, S400 & Li-ion \\
& & Smart EV $(2010)$ & NiMH \\
\hline Mitsubishi & Japan & iMiEV $(2010)$ & Li-ion \\
\hline Nissan & Japan & Altima & Li-ion \\
& & Leaf EV $(2010)$ & Li-ion \\
\hline Tesla & USA & Roadster(2009) & Sodium/Metal Chloride \\
\hline Think & Norway & Think EV & \\
& & & \\
\hline
\end{tabular}




\subsubsection{Li-ion Batteries}

Li-ion batteries are popular nowadays due to their significant life span and quality of their charge. In general, charging and discharging batteries is a chemical reaction, but Li-ion technology is claimed as an exception [23]. In Li-ion technology energy flows in and out as part of ion movement between anode and cathode. The Li-ion charger is a voltage-limiting device that is comparable to the lead acid system. The difference lies in a higher voltage per cell, tighter voltage tolerance and the absence of trickle or float charge at full charge [23]. Because of all the above-mentioned facts, lithium ion batteries are the most popular in PEVs. Correct setting of the Li-ion chargers is crucial because Li-ion cannot accept overcharge. Most lithium ion cells charge to $4.20 \mathrm{~V} /$ cell with a tolerance of $\pm 50 \mathrm{mV} /$ cell. Higher voltages could increase the capacity, but the resulting cell oxidation would reduce battery's life cycle. However, safety concerns are more crucial than battery life cycle if battery charges beyond $4.20 \mathrm{~V} /$ cell [23].

Figure 2.2 indicates the different levels of Li-ion voltage and current behavior in different stages. There are four main stages in the charging process of Li-ion batteries. Stage 1 is when the voltage increases at the constant current. This process takes 1 to 1.5 hour. Stage 2 is the time interval that voltage is maximum, while the current starts to decrease. This time interval lasts approximately 2 hours. Stage 3 is charge termination that happens when the current is smaller than $3 \%$ of the maximum current. Last but not 


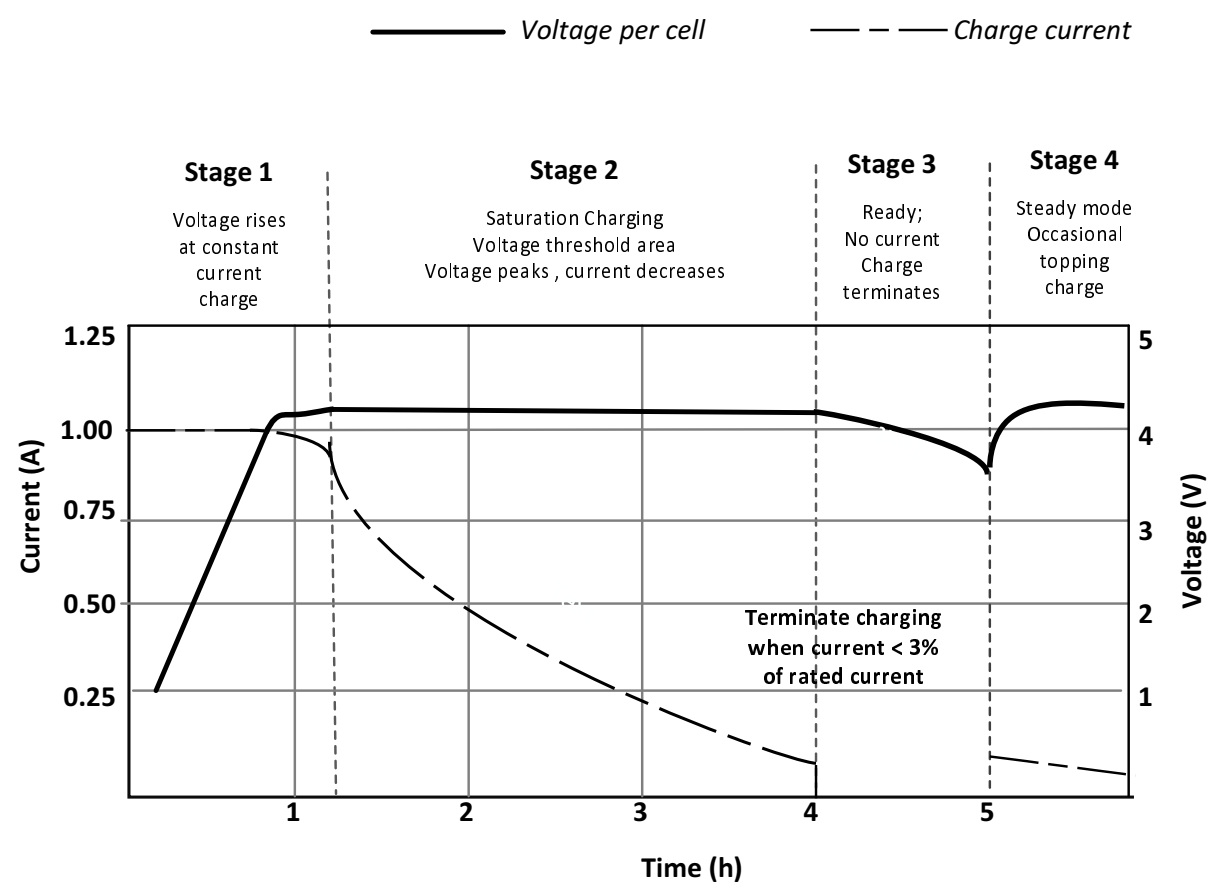

Figure 2.2: Charging profile of a Li-ion battery cell [23].

least is the final stage (stage 4) which is occasional topping charge process. In this stage, topping charge will be applied to battery cell when the voltage drops to $4.05 \mathrm{~V} /$ cell.

When the current drops to a predetermined level, Li-ion is fully charged.

Today, the battery industry uses C-rate to scale the charge and discharge current of a battery [23]. The charge rate of a typical Li-ion battery is between $0.5 \mathrm{C}$ and $1 \mathrm{C}$ in Stage 1 , and the charge time is about three hours. Manufacturers recommend charging the 18650 cell at $0.8 \mathrm{C}$ or less. Charge efficiency is 97 to 99 percent, and the cell remains cool during charge. Some Li-ion battery packs may experience a temperature rise of about 5 ${ }^{\circ} \mathrm{C}\left(9{ }^{\circ} \mathrm{F}\right)$ when reaching full charge [23]. On discharge, the process is reversed, and the 


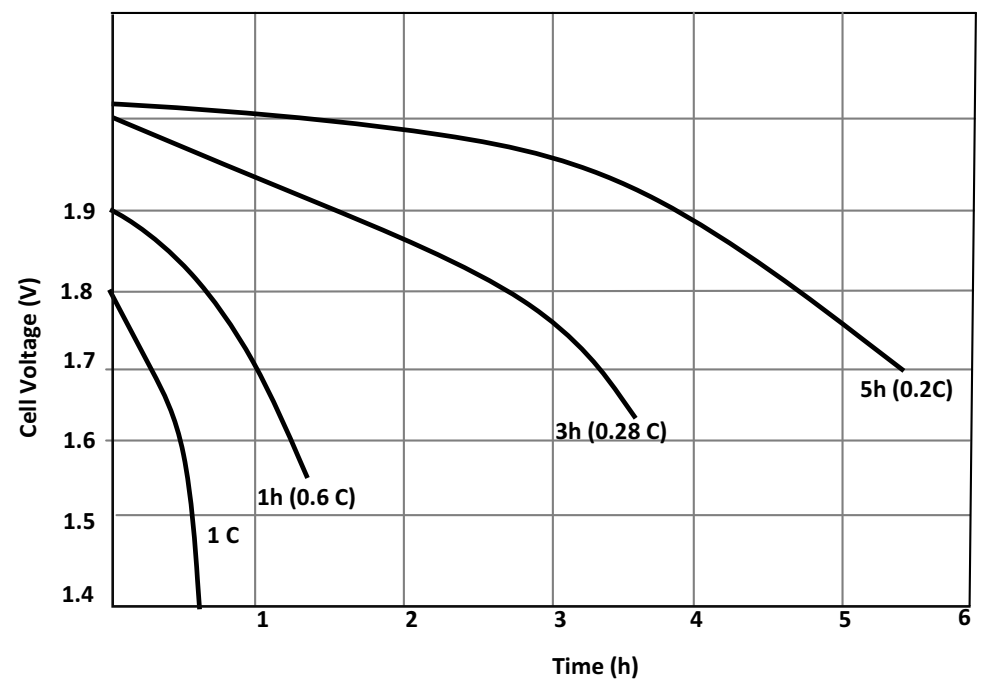

Figure 2.3: Discharging profile of a Lead acid battery cell [16].

C-rate defines how fast the battery will discharged over time.

Discharging battery behavior has to be analyzed with a battery analyzer. Battery analyzer is capable of applying different C-rates and checks how battery responds to desired discharging rate. Higher C-rate will produce a lower capacity reading and vice versa. For example, by discharging the 1,000 $\mathrm{mAh}$ battery at $2 \mathrm{C}(2,000 \mathrm{~mA})$, the battery should ideally deliver the full capacity in 30 minutes [23]. In reality, internal resistance and environment temperature turn some of the energy into heat and lowers the resulting capacity to about 95 percent or less. Discharging the same battery at $0.5 \mathrm{C}$, or $500 \mathrm{~mA}$ over two hours will likely increase the capacity to above 100 percent. Figure 2.3 illustrates the different discharging times of a lead acid battery at various load in C-rate. 


\subsection{Schematics of Possible PHEV Architectures}

EVs and PHEVs have similar architecture, although PHEVs have an internal combustion engine (ICE). PHEVs also have more complex and advanced architectures and control system in comparison with EVs. One advantage of PHEVs is fuel flexibility. A user could power their vehicle with electricity from the electrical power grid, gasoline (or other liquid fuel), or both. To do so, a PHEV has both an electric motor and an ICE. This flexibility also complicates vehicle designs and possible ways of using energy from two different systems [24]. The objective of the overall design of PHEVs system is to supply power from two different sources.

Series, Parallel, and Power-split are three different existing architectures for PHEVs. Each configuration is unique and has it's own advantages and disadvantages. None of existing architecture is preferable over other ones. While Toyota is currently developing a PHEV with a parallel architecture, i.e. a plug-in version of the Prius, General Motors is working with a series architecture, i.e. the Chevy Volt [24].

\subsubsection{Series PHEV Architecture}

In general, series hybrid vehicles require larger electronic components including both motor and generator, resulting in a more weighty drive-train system [25]. Figure 2.4(a) shows series PHEV architecture. A series drivetrain architecture powers the vehicle only 


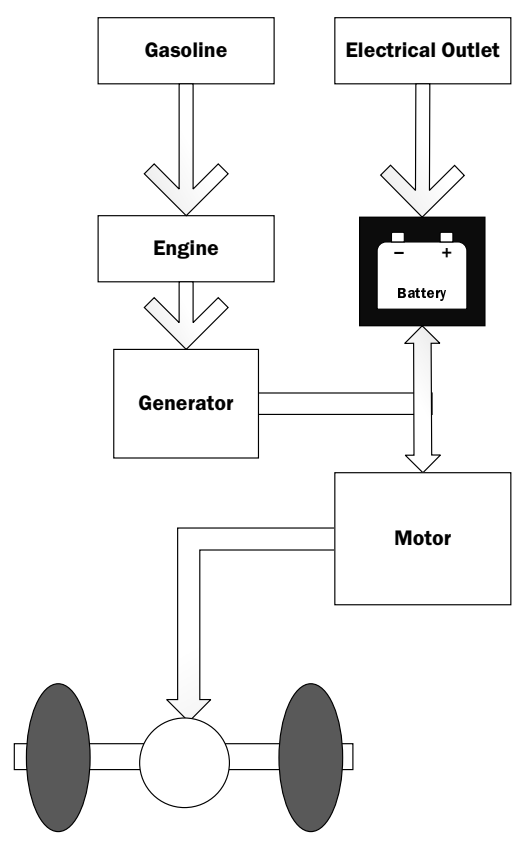

(a) Series power-train architecture

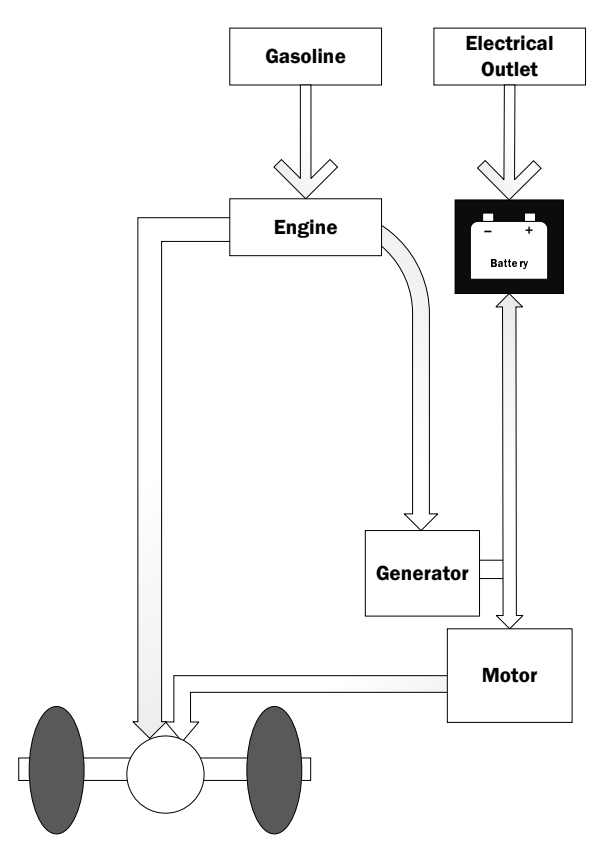

(b) Parallel power-train architecture

Figure 2.4: Fundamental of PHEV architecture [24].

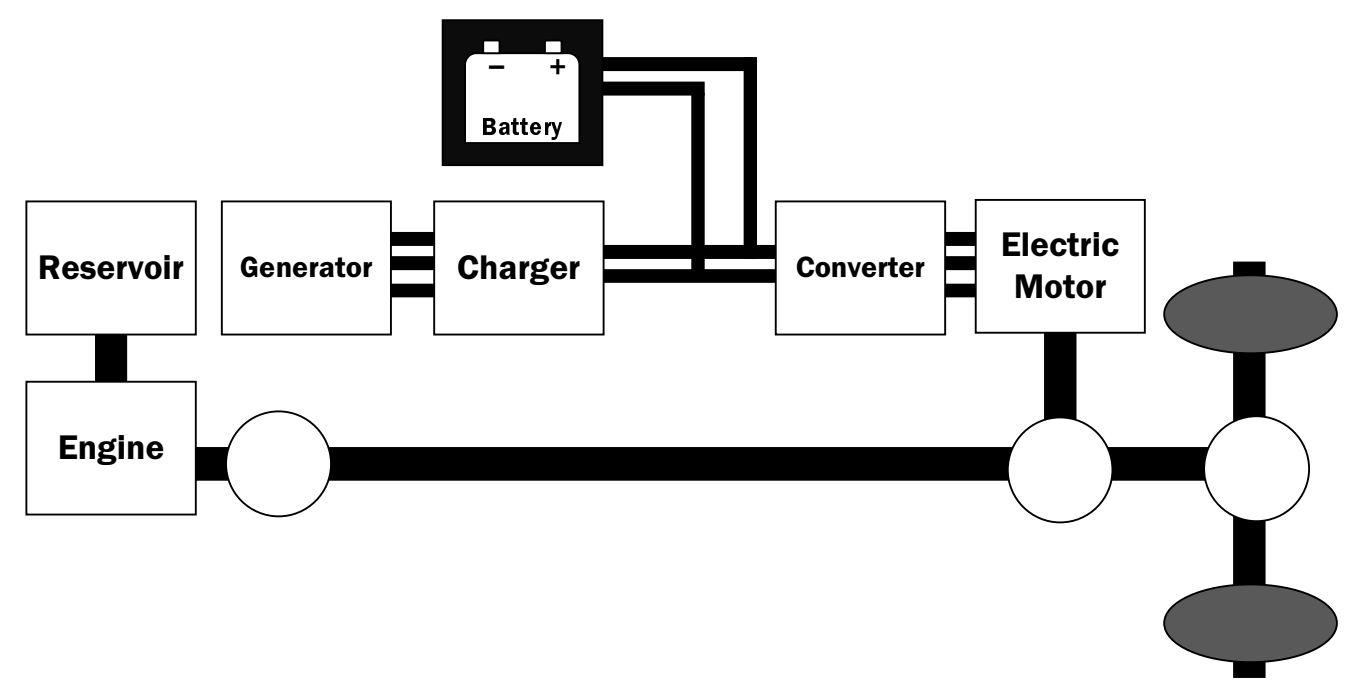

Figure 2.5: Power-split PHEV architecture [25]. 
by an electric motor using electricity from a battery. The battery is charged from an electrical outlet, or by the gasoline engine via a generator. Series power-trains are understood to be most suited to medium and heavy duty PHEVs because of the additional space that is available for the components and the vehicle platform $[26,27]$. In the series configuration, the vehicle can aim for optimum operation due to the mechanical decoupling of the engine. Also, the electric motor can reach very high Revolutions Per Minute (RPM) which leads to cheaper price due to less required gear in the transmission. Moreover, this configuration can perform All Wheel Drive (AWD) performance due to its advantage of using one electric motor per wheel. Despite all the mentioned advantages, series architecture has some considerable disadvantages. The conversion of ICE happens twice (mechanical to electrical, electrical to mechanical) and therefore losses are significant. Also it requires full-sized ICE and electric motor, since the battery does not have a high storage capacity.

\subsubsection{Parallel PHEV Architecture}

A parallel drivetrain adds a direct connection between the engine and the wheels, adding the potential to power the vehicle by electricity and gasoline simultaneously or by gasoline only. Figure2.4(b) shows parallel architecture configuration. Parallel architecture has a pure electric traction that is boosted by a battery pack at low speed. It also has 
a hybrid action where both engine and battery are engaged in this configuration. Speed and torque of the two powerplants can be chosen independently, which leads to smaller powerplants and cheaper and more efficient vehicle in comparison with the series configuration. Complex control system configuration is the disadvantage of this model in compared to series architecture.

\subsubsection{Power-Split PHEV Architecture}

Power-split configuration is a combination of series and parallel architecture. Therefore, the alternative term of series-parallel hybrid is appropriate. Figure 2.5 shows the power-split hybrid configuration. There is a direct mechanical power path as well as an electromechanical path for the ICE. Existing pure electrical traction are boosted by batteries at low speed. Hybrid traction using both engine and battery is a good option for this type of vehicles. Battery charges during engine traction and regenerative braking action. Power-split architecture is the combination of series and parallel configuration and uses the advantages of both model. The increase in cost and further complexity in this configuration control system are unavoidable disadvantages of this architecture.

Power-split is the most popular concept in full EVs and PHEVs [28]. GM-Allison EVT is an example of this architecture. In this study, the power-split configuration was simulated due to its popularity in industry. 


\subsection{PHEV Battery Discharging Concept}

Charge Depleting (CD) and Charge Sustaining (CS) are two basic modes of a PHEV. Charge depleting (CD) is the mode of vehicle operation that is dependent on energy from the battery pack. Battery electric vehicles operate solely in this mode. Most PHEV operate in CD mode at start-up and switch to CS mode after the battery has reached its minimum SOC. Usable DOD is the difference between the maximum and minimum SOC [24]. In Figure 2.6, the battery is "fully" charged (from an electrical outlet) to 98 percent at the beginning of a cycle. For a distance, the PHEV is driven in CD mode. Energy stored in the battery is used to power the vehicle, gradually depleting the battery's SOC. Once the battery reaches minimum level (around 25\% to 30\% depending on the different types of vehicle battery pack), the vehicle switches to CS mode. In CS mode,

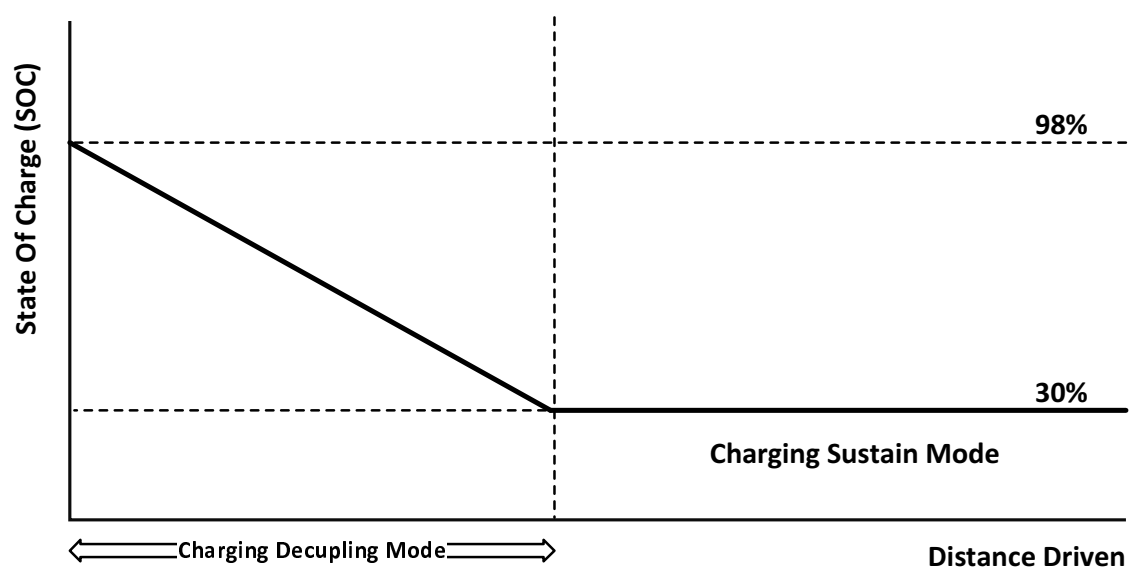

Figure 2.6: Different stage of SOC behavior in PHEVs [24]. 
the SOC is sustained by relying primarily on the gasoline engine to drive the vehicle, using the battery and electric motor to increase the efficiency of the gasoline engine. The vehicle remains in CS mode until the battery is plugged in again to recharge. PHEV uses all-electric or blended operation in CD mode [24].

In conclusion, PEVs need to charge immediately in CS mode. Therefore, an accessible charging station is essential to recharge electric vehicles. In chapter 3 , The relationship between PEVs and stations is researched comprehensively. 


\section{Chapter 3}

\section{Driving Cycles and State of Charge}

\section{Analysis}

\subsection{Introduction}

Transport Canada's Eco TECHNOLOGY for Vehicles program ("eTV") tests emerging vehicle technologies to assess their performance in accordance with established Canadian motor vehicle standards. Test vehicles will undergo the following three phases of testing and evaluation:

Phase 1: Laboratory Fuel Consumption and Emissions Testing.

Phase 2: Dynamic Performance Testing. 
Phase 3: On-road Evaluations.

Phase 1 focuses on the various effects of different kinds of fuel on vehicles. It also evaluates the outcomes against Canadian and U.S standards. Moreover, emissions and fuel consumption tests will performed as per the procedures listed on the Code of Federal Regulations (CFR) [29]. Phase 2 focuses on dynamic performance tests which are performed by Transport Canada testing facility. The test's emphasis is on road safety of transportation. The last phase (phase 3) of evaluation will be performed by having drivers or evaluators drive the test vehicle for a certain distance and then respond to evaluation forms. The results of all three phases conclude in a final report which will be available to the manufacturer as well as stakeholders. Also, some highlighted results will be available through related websites. Fuel Consumption and Emissions Testing and Analysis in phase one is the main focus of this thesis and research analysis.

\subsection{Driving Cycles}

A drive cycle is a pattern of changing accelerations, speeds, and braking over time used to test fuel economy, as well as battery performance [25]. A cycle usually repeats one or more schedules. The SOC discharging behavior of PEV's battery is directly relevant to the acceleration and de-acceleration of vehicle and also road and seasonal conditions. Studying SOC behavior for different cycles leads to understanding of PEV driving range 
and battery behavior. The driving cycles are derived from extensive data on real-world driving conditions, such as driving activity, trip length and stopping frequency, among other factors [30].

There are several driving standards such as Economic Commission for Europe Dynamometer Operating Cycles, Japanese Technical Standards, and California EPA Air Resources Board Dynamometer Driving Schedules. These driving cycles are not the main focus on this study since they are mostly designed for testing combustion engines. However, the Society of Automotive Engineers (SAE) and the U.S. Environmental Protection Agency (EPA) are developed recommended practices and procedures for the testing vehicles which is more suitable for PEV's battery behavior study [31].

\subsubsection{U.S. Environmental Protection Agency (EPA)}

There are several EPA driving cycles to consider for different scenarios in vehicles. However, not all provided driving cycles are suitable for PEVs. The most important EPA classifications which are suitable for PEVs come as followed:

U.S. FTP-72 Cycle (LA-4, Urban): The U.S. FTP-72 or LA-4 driving cycle is a simulation of a $12.07 \mathrm{~km}$ urban driving route, at a standard temperature and pressure (STP). The Federal Test Procedure 72 has a running time of 1369 second (22

minutes and 49 seconds). The length of this driving cycle is $12.07 \mathrm{~km}$ with a top 


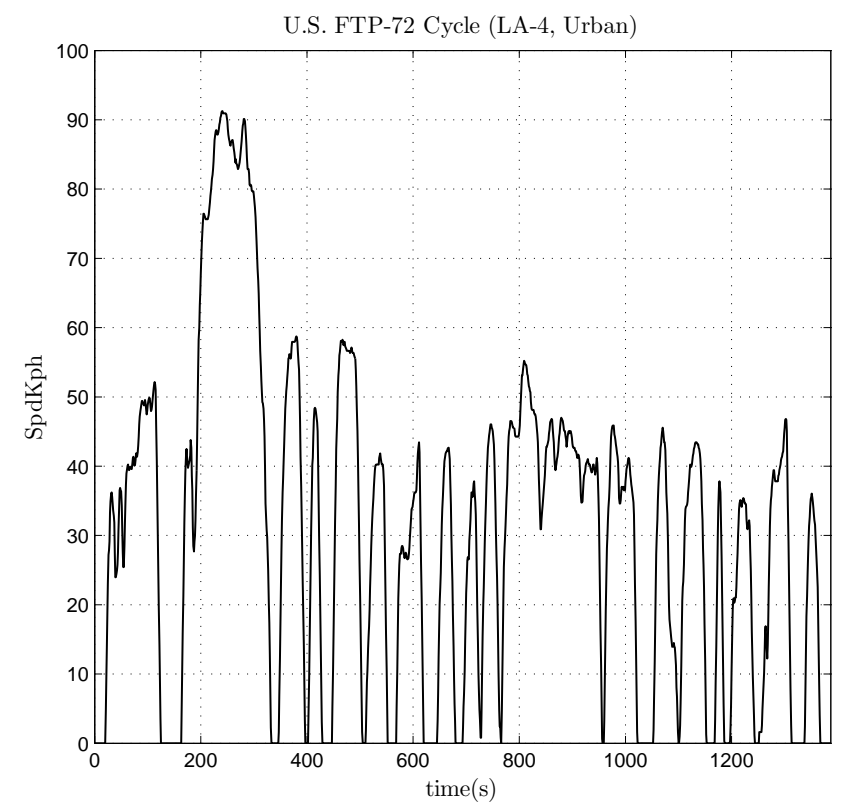

Figure 3.1: The U.S. FTP-72 simulated driving cycle, length of 1369 seconds, average speed of $31.5 \mathrm{~km} / \mathrm{h}, 18$ total stops, and distance of $12.07 \mathrm{~km}$.

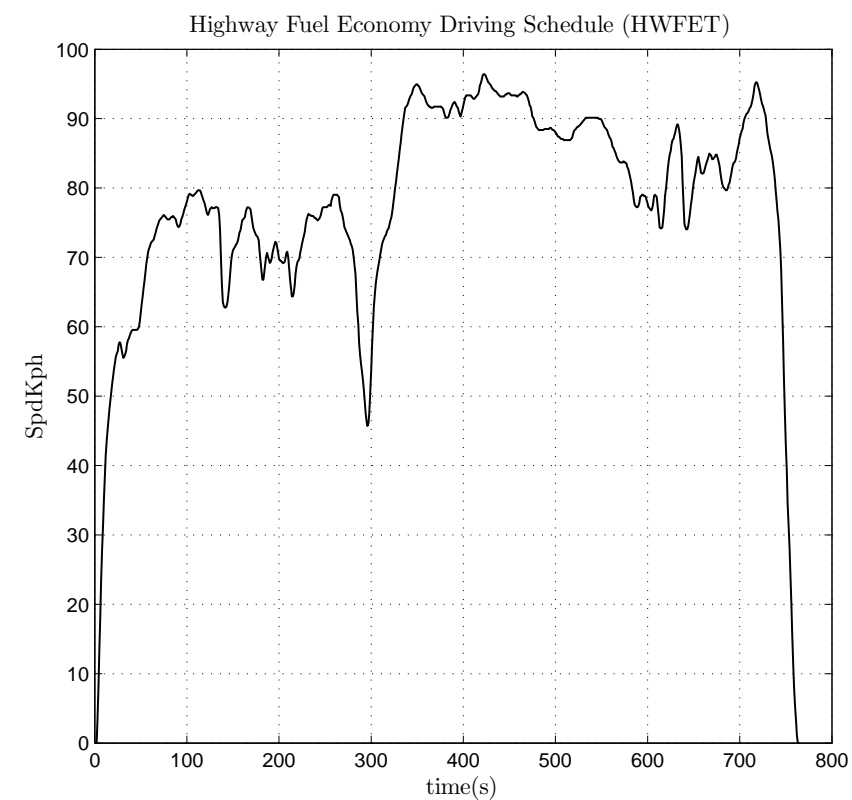

Figure 3.2: The U.S. HWFET simulated driving cycle, length of 765 seconds, average speed of $77.73 \mathrm{~km} / \mathrm{h}$, and distance of $16.51 \mathrm{~km}$. 
speed of $91.3 \mathrm{~km} / \mathrm{h}$ and average speed of $31.5 \mathrm{~km} / \mathrm{h}$. FTP-72 contains 18 stops in total. Figure 3.1 indicates the simulated FTP-72 driving cycle standard.

Highway Fuel Economy Test (HWFET) : The Highway Fuel Economy Test (HWFET) driving cycle is a simulation of a highway driving route that is approximately 16 $\mathrm{km}$ long. The maximum speed of the cycle is $96.5 \mathrm{~km} / \mathrm{h}$ and the minimum speed is $45.7 \mathrm{~km} / \mathrm{h}$. The HWFET has a running time of 765 seconds. Figure 3.2 indicates the simulated Highway Fuel Economy Driving Schedule standard.

SC03: The SC03 Supplemental Federal Test Procedure (SFTP) has been introduced to represent the engine load and emissions associated with the use of air conditioning (A/C) in vehicles. SCO3 driving cycle has a running time of 596 seconds (9 minutes and 56 seconds). The length of this driving cycle is $5.8 \mathrm{~km} .88 .2 \mathrm{~km} / \mathrm{h}$ is the achieved top speed with the average speed of $34.8 \mathrm{~km} / \mathrm{h}$. Figure 3.3 indicates the US03 driving cycle standard.

US06: The US06 Supplemental Federal Test Procedure (SFTP) was developed to address the shortcomings with the FTP-72 test cycle in the representation of aggressive, high speed and/or high acceleration driving behavior, rapid speed fluctuations, and driving behavior following startup [32]. US06 duration is 596 second (9 minutes and 54 seconds). It has a $13 \mathrm{~km}$ driving routine with an average speed of $77 \mathrm{~km} / \mathrm{h}$. Top speed is $130 \mathrm{~km} / \mathrm{h}$ and it includes four stops. Figure 3.4 indicates the US06 


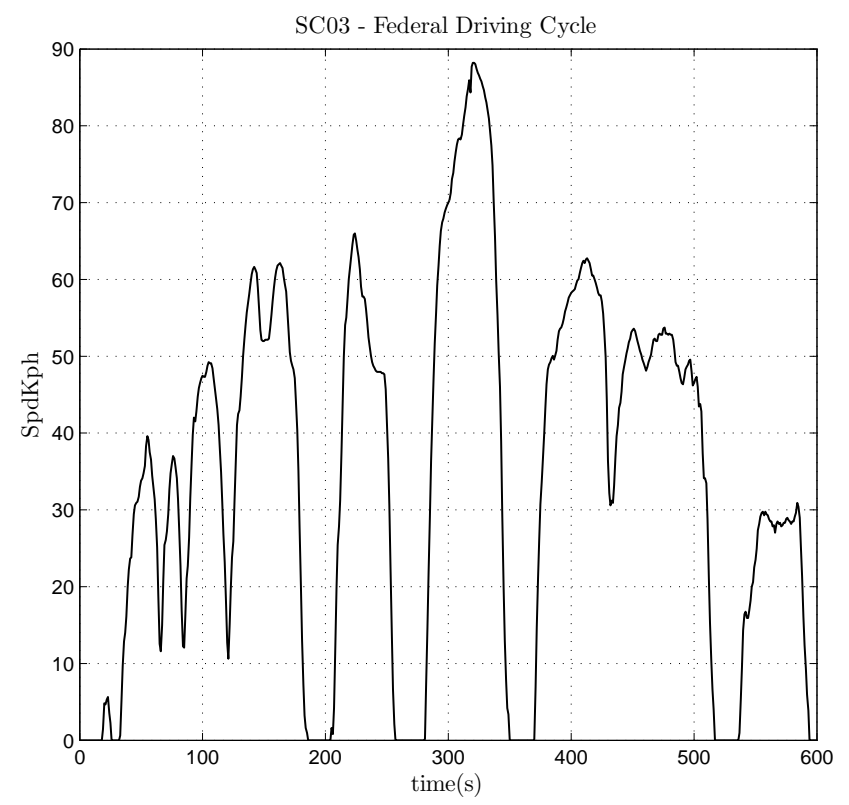

Figure 3.3: SC03 speed correction driving schedule, length of 596 seconds, average speed of $34.8 \mathrm{~km} / \mathrm{h}$, and distance of $5.8 \mathrm{~km}$.

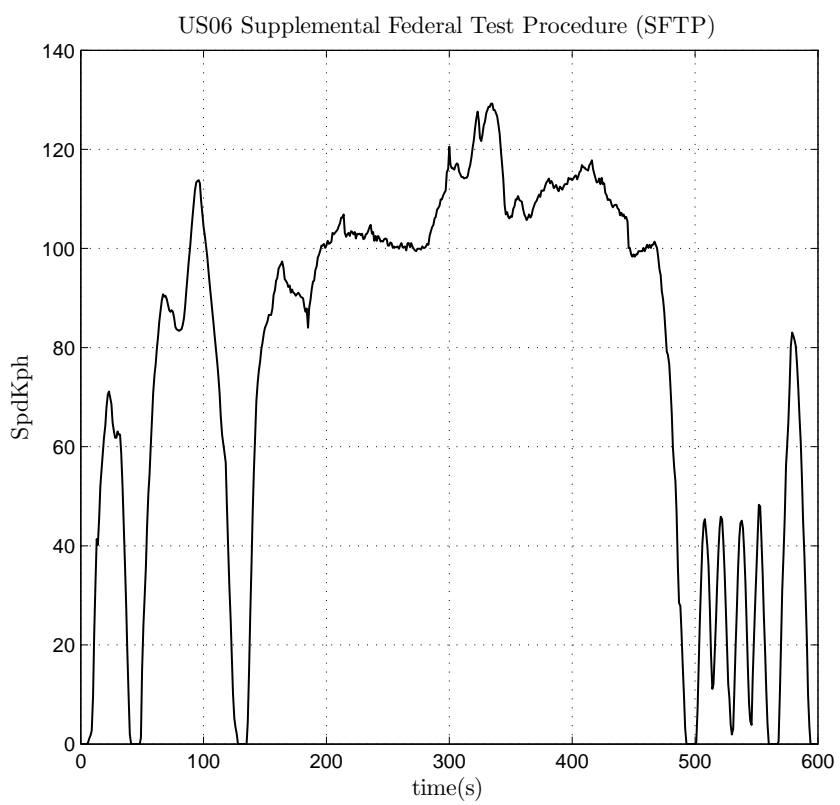

Figure 3.4: US06 or supplemental FTP driving schedule, length of 596 seconds, average speed of $77.4 \mathrm{~km} / \mathrm{h}$, and distance of $12.8 \mathrm{~km}$. 
driving cycle standard.

\subsection{Plug-in Electrical Vehicle Model}

As it is stated in chapter 2, PHEVs models are more complex than EVs especially when it comes to control system design. By modifying predefined Mathworks hybrid-electric vehicle model, we are simulating different standard driving scenarios. This predefined model is designed for system-level tests or power quality analysis. we have modified this model to help us analyse and study SOC behavior in different circumstances.

PEV model consists of physical and control systems. Integration of PEV model with MATLAB and Simulink enables us to understand PEV's battery behavior. Development of battery discharging profiles help us realize when PEVs battery pack needs to be charged.

\subsubsection{Vehicle and Battery Model Simulation}

Our simulated PHEV contains electrical, mechanical, thermal, mode logic and control systems in Figure 3.5. Vehicle block includes tire and inertial models. Electrical system contains, synchronous motor and generator, DC-DC converter and a battery pack. The power-split architecture of PHEVs in Figure 2.5 was employed to configure this simulation blocks. There are various types of configurations which are suitable for bat- 
tery simulation. Simelectronic library contains generic predefined models of batteries. Generic predefined model is a charge dependent voltage source where it's parameters can be found in existing data sheets in Simulink environment. The advantage of this battery model is to define different types of batteries, while it also has a few parameters which can be found easily on relative data sheets. On the other hand, Simpower library provides several pre-defined models with full parameterization and extensive documentation.

Although these models are compelling, more realistic and customized battery cell model is required to understand the discharge characteristic of PEVs and PHEVs. For custom cell battery model, Simscape language was used along with battery cell equivalent discharge circuit. Figure 3.6 indicates the custom battery with 10 battery cells where each battery cell contains a discharge equivalent circuit based on Figure 2.1. DC-DC converter is modeled using Simscape for simplicity in compared to Simpower library.

Full vehicle model block contains tire models and longitudinal dynamics. Since the combustion engine is not the main focus on this simulation, a lookup-table relating speed to available power was used for simplicity.

\subsubsection{Logic Mode}

Figure 3.7 shows the specification of mode logic in PEVs. A PEV in motion has 3 different modes. In Start mode, the generator is used as a starter motor to start the engine and 


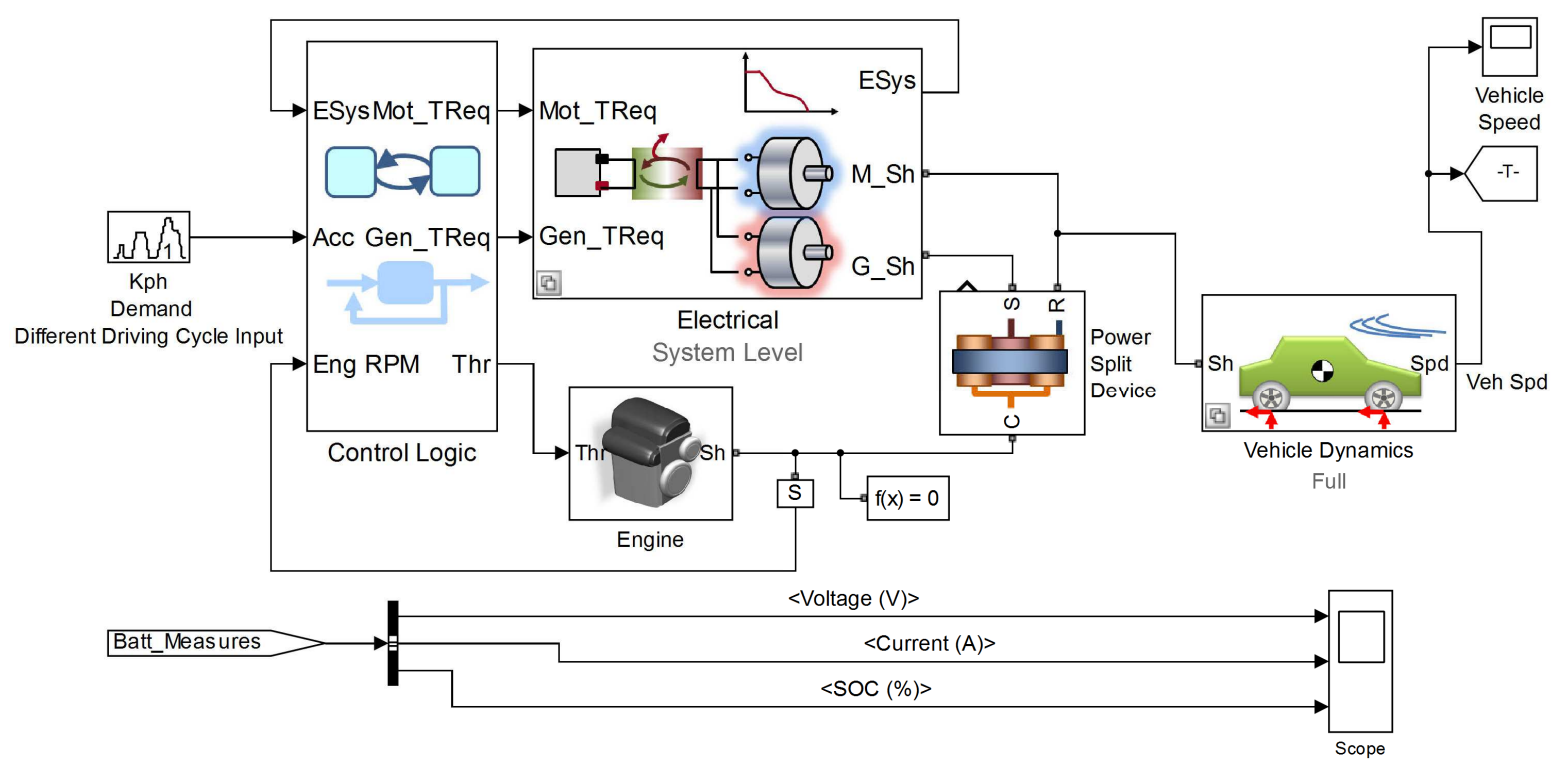

Figure 3.5: Simulated configuration of PHEV block parameter including control logics, electrical system level, power split device, vehicle dynamics, and mechanical engine block.

the electrical motor is used to drive the vehicle. When the engine reaches the certain threshold (800 RPM), vehicle enters a normal mode where the engine is used to drive the vehicle and charge the battery. If the driver wishes to accelerate, the motor can be used to drive the vehicle faster while the generator is off. This means all the vehicle torque can be used to accelerate the vehicle. In cruise mode, the generator may be used to charge the battery. Moreover, there is expected transmission between acceleration mode and start mode. The motor is used to charge the battery when the driver applies brake. For building the mode logic, Stateflow in Simulink environment was used. The logic mode 


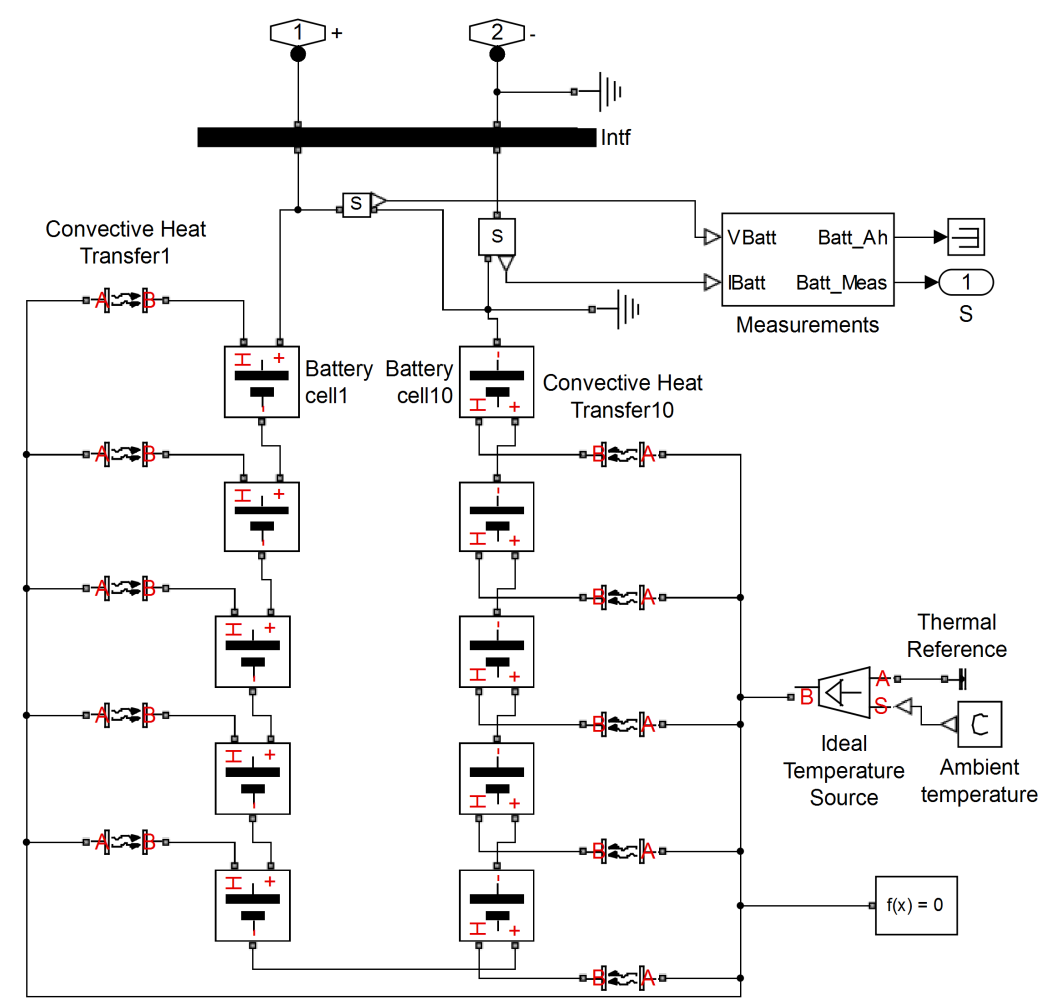

Figure 3.6: Customized battery with 10 battery cells for PHEV model.

for this simulated vehicle locates in control subsystem in Figure 3.5. Logic block takes the vehicle speed, battery charge (SOC), applied brake and engine speed as inputs then evaluates the performing state for our simulated vehicle. Generator and motor are either enable or disable based on evaluated state. 


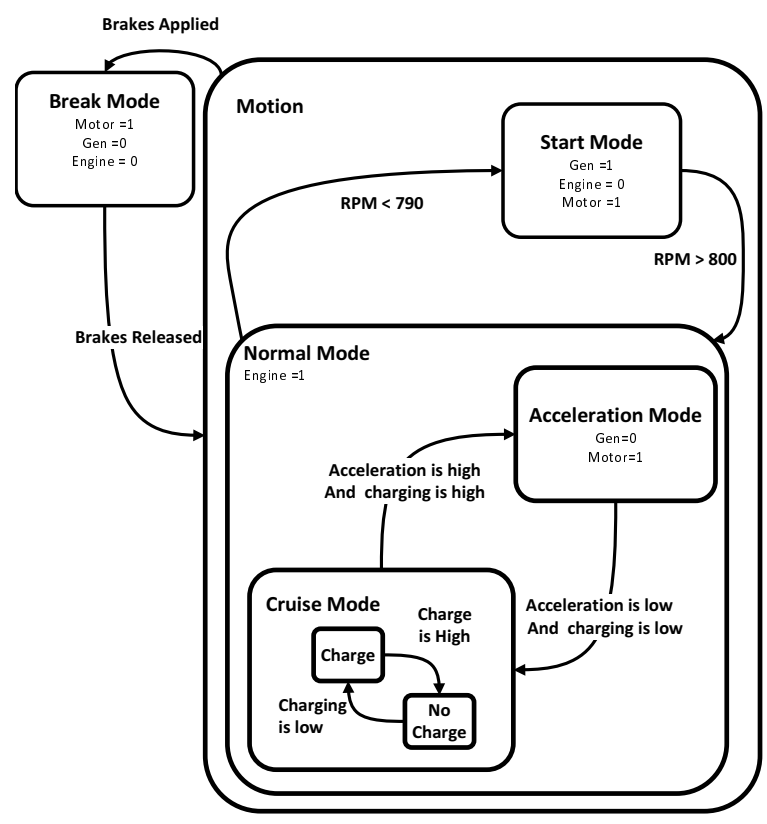

Figure 3.7: Mode logic specification flow chart for PHEV.

\subsection{Results and Post Processing}

Our designed model helps us to test all U.S. EPA driving cycles. All driving cycles were repeated until the battery pack had been depleted to $30 \%$ or less. In other words, driving cycles were repeated until simulated PHEV battery switch from CD to CS mode. A sufficient number of tests had been ran to determine discharging time in each standard cycle.

For each driving cycle a battery discharging profile was created for further applications. 


\subsubsection{FTP-72 Post Analysis}

FTP-72 in Figure 3.1 was selected as our first input to our model. As expected, the SOC behavior followed the driving cycle pattern. Since the initial SOC was different each time, DOD varied for each iteration. Figure 3.8(a) indicates the DOD of the first simulated cycle where the initial charge was $98 \%$. SOC fluctuation is caused by acceleration, deacceleration and applied break. Table 3.1 demonstrates DOD for our modeled battery pack through numerous driving cycles until it reaches the CS mode. Results indicate the average DOD of $7 \%$ in each iteration. An average linear discharging behavior was created considering DOD in each FTP-72 cycle to demonstrate a general discharging profile for our battery pack. Figure 3.8(b) show that the curve has exponential behavior and it takes more than 200 minutes to discharge from a full initial charge.

Table 3.1: FTP-72 driving cycle electrical consumption results.

\begin{tabular}{|c|c|c|c|}
\hline FTP-72(LA-4) Cycle & Initial SOC (\% ) & End SOC (\% ) & Drop (\%) \\
\hline \hline 1 & 98 & 95.5 & 2.5 \\
\hline 2 & 95.5 & 92.4 & 3.1 \\
\hline 3 & 92.4 & 87.5 & 4.9 \\
\hline 4 & 87.5 & 77.7 & 9.8 \\
\hline 5 & 77.7 & 70.7 & 7 \\
\hline 6 & 70.7 & 62.7 & 8 \\
\hline 7 & 62.7 & 53.3 & 9.4 \\
\hline 8 & 53.3 & 43.2 & 10.1 \\
\hline 9 & 43.2 & 32.2 & 11 \\
\hline
\end{tabular}




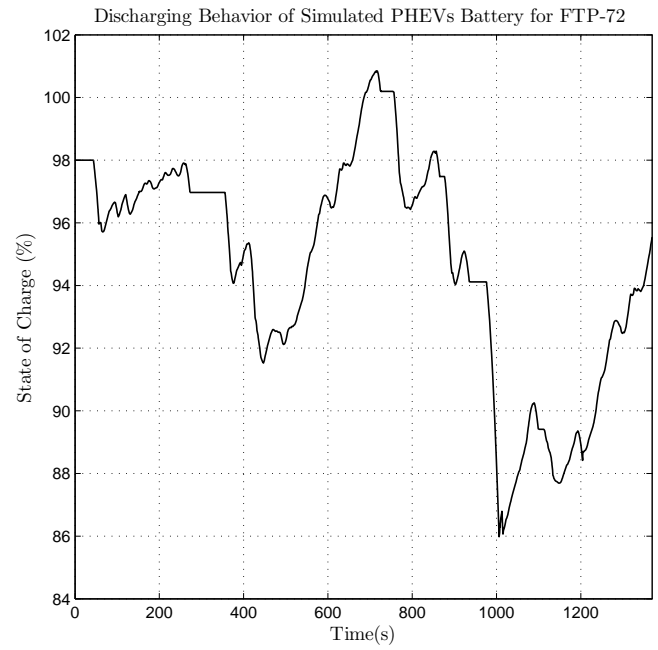

(a) FTP-72 discharging behavior of initial cycle.

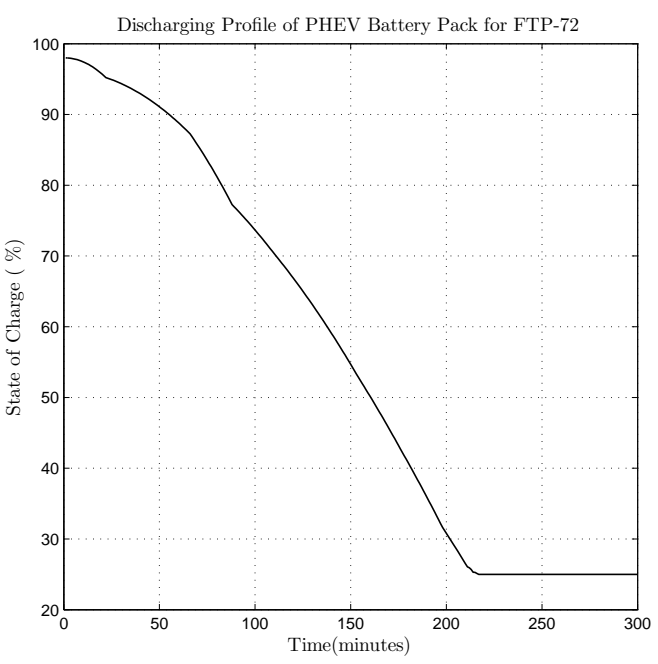

(b) FTP-72 overall PHEV battery discharging profile.

Figure 3.8: Discharging profile of Electric Vehicle battery obtained using FTP-72 driving cycle standard.

\subsubsection{HWFET Post Analysis}

HWFET was the second tested driving cycle as it indicated in Figure 3.2. Since duration of each HWFET is short, two cycles were used for each iteration. Figure 3.9(a) indicates the DOD for first simulated iteration when the initial charge was $98 \%$. SOC fluctuation is caused by acceleration, de-acceleration and applied break. The Amplitude of SOC fluctuation is less than FTP-72, although the DOD for each iteration was greater than FTP-72 due to the higher achieved speed on highways. Table 3.2 demonstrates the DOD of the battery pack when it runs through numerous driving cycles. Results indicate the average DOD of $8.75 \%$ in each iteration. Therefore, DOD in HWFET driving cycle is 
more significant compared to FTP-72. Based on DOD in each simulated iteration in Table 3.2, an average linear discharging behavior was created to demonstrate the general discharging profile for our battery pack. Figure 3.9(b) shows that the curve has an exponential behavior and it takes more than 100 minutes to reach to CS mode with full initial charge.

Table 3.2: HWFET driving cycle electrical consumption results.

\begin{tabular}{|c|c|c|c|}
\hline HWFET Cycle & Initial SOC (\%) & End SOC (\%) & Drop (\%) \\
\hline \hline $1 / 2$ & 98 & 87 & 11 \\
\hline $3 / 4$ & 87 & 66.8 & 20.2 \\
\hline $5 / 6$ & 66.8 & 47.2 & 19.6 \\
\hline $7 / 8$ & 47.2 & 23 & 24.2 \\
\hline
\end{tabular}

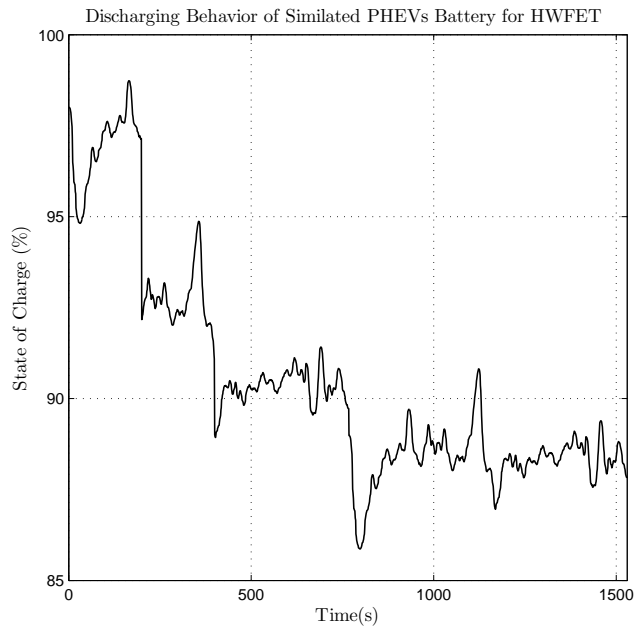

(a) HWFET discharging behavior of initial cycle.

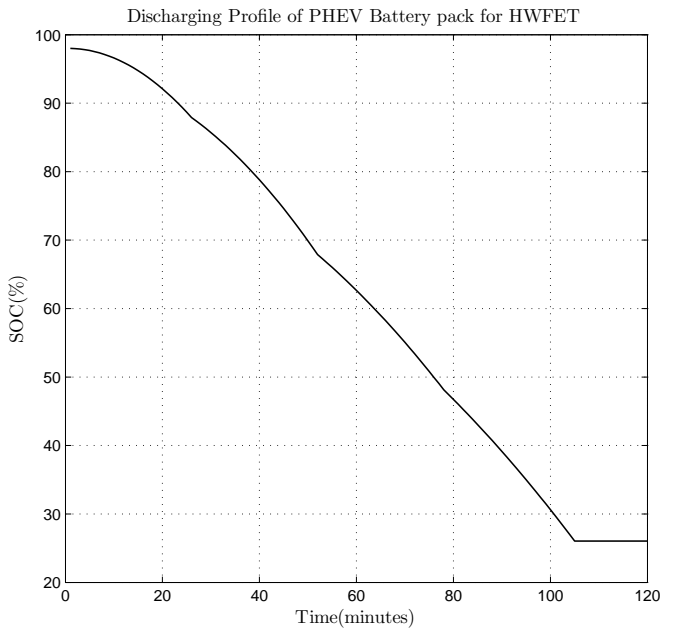

(b) HWFET overall PHEV battery discharging profile.

Figure 3.9: Discharging profile of electric vehicle battery obtained using HWFET driving cycle standard. 


\subsubsection{SC03 Post Analysis}

SC03 driving cycle in Figure 3.3 was applied to our model. Figure 3.10(a) indicates the discharging curve for the first simulated cycle when the initial charge was $98 \%$. The SOC fluctuation has a sinusoidal behavior due to the aggressive driving pattern of SC03.

The amplitude of the fluctuation was increased as battery discharged over time. Table 3.3 demonstrates the DOD of the battery when it runs through numerous driving cycles. Results indicate the average DOD of $11 \%$ in each cycle. Therefore, the DOD in this cycle is a bit higher than FTP-72 and lower than HWFET. Based on DOD in each simulated iteration in Table 3.3, an average linear discharging behavior was created to demonstrate the general discharging profile for our battery pack. Figure3.10(b) show that the curve has an exponential behavior and it takes more than 120 minutes for the battery to reach to CS mode with full initial charge.

Table 3.3: SC03 driving cycle electrical consumption results.

\begin{tabular}{|c|c|c|c|}
\hline SC03 Cycle & Initial SOC (\% ) & End SOC (\% ) & Drop (\%) \\
\hline \hline $1 / 2$ & 98 & 92 & 6 \\
\hline $3 / 4$ & 92 & 81.5 & 10.5 \\
\hline $5 / 6$ & 81.5 & 64.7 & 16.8 \\
\hline $7 / 8$ & 64.7 & 52 & 12.7 \\
\hline $9 / 10$ & 52 & 43 & 9 \\
\hline $11 / 12$ & 43 & 32 & 11 \\
\hline
\end{tabular}




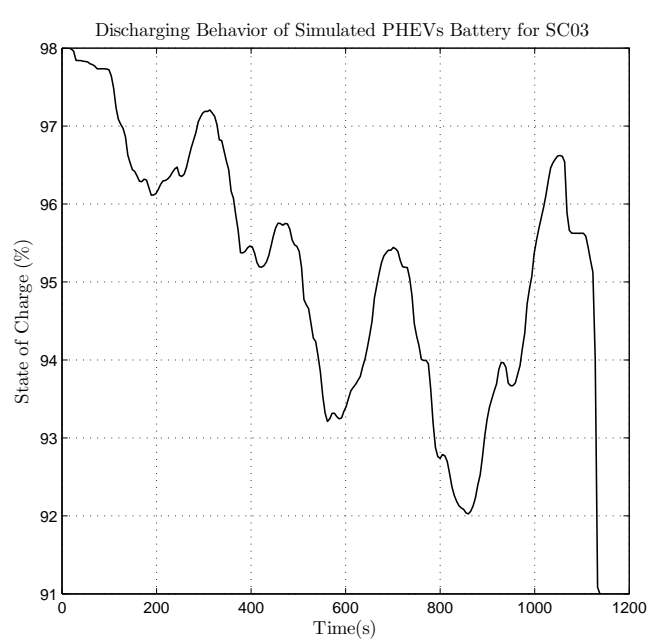

(a) SC03 discharging behavior of initial cycle.

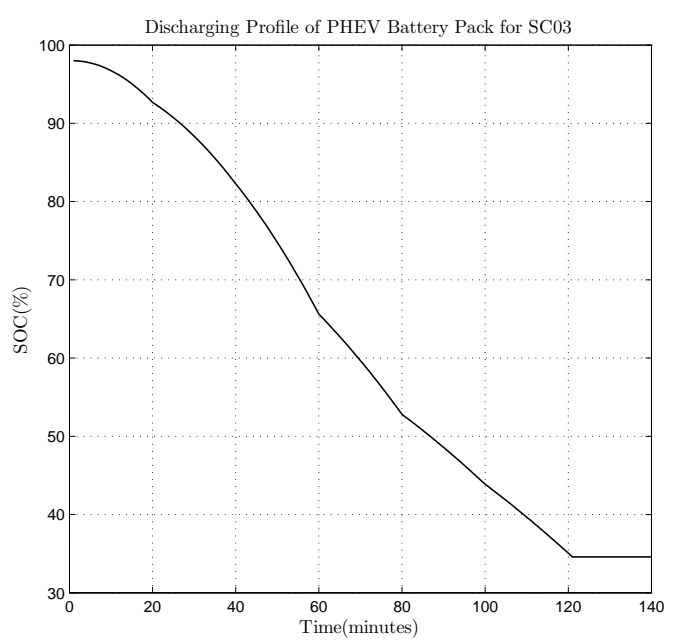

(b) SC03 overall PHEV battery discharging profile.

Figure 3.10: Discharging profile of electric vehicle battery obtained using SC03 driving cycle standard.

\subsubsection{US06 Post Analysis}

US06 was the last driving cycle analysis in this chapter, which is indicated in Figure 3.4.

Since the initial SOC was different each time, DOD varied for each iteration. Figure 3.11(a) indicates the discharging curve for the first simulated cycle when the initial SOC was $98 \%$. Acceleration, de-acceleration and applied break in this cycle caused a sawtooth shape fluctuation for SOC. Table 3.4 demonstrates the DOD of our battery pack when it runs through numerous driving cycles. Results indicate an average DOD of $20 \%$ for each cycle. Therefore, the DOD is the highest in comparison with other tested driving cycles. Based on DOD in each simulated iteration in Table 3.4, an average linear discharging behavior was created to demonstrate the general discharging profile for our battery pack 


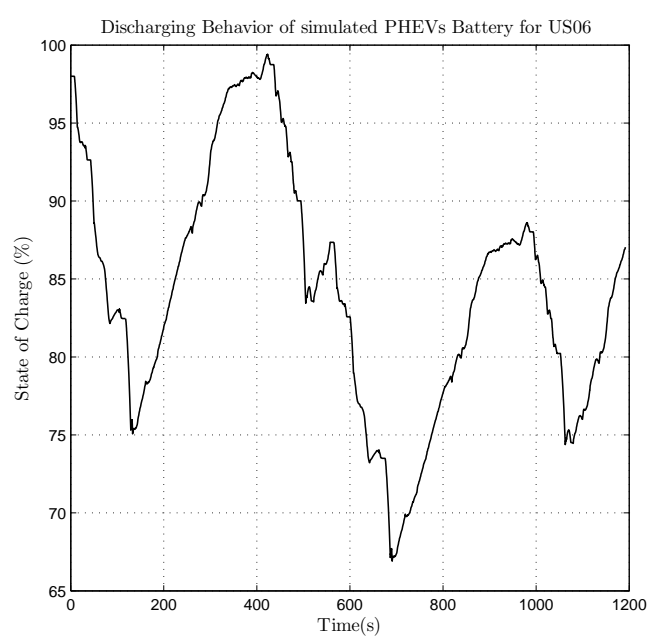

(a) US06 discharging behavior of initial cycle.

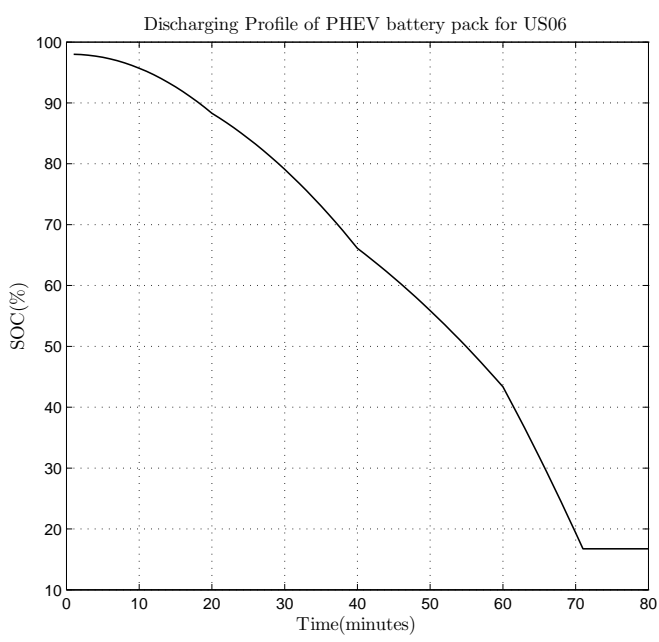

(b) US06 overall PHEV battery discharging profile.

Figure 3.11: Discharging profile of electric vehicle battery obtained using US06 driving cycle standard.

for SC03. Figure 3.10(b) demonstrates, the curve has exponential behavior and it takes around 70 minutes to reach to CS mode with full initial charge.

Table 3.4: US06 driving cycle electrical consumption results.

\begin{tabular}{|c|c|c|c|}
\hline US06 Cycle & Initial SOC (\% ) & End SOC (\% ) & Drop (\%) \\
\hline \hline $1 / 2$ & 98 & 87 & 11 \\
\hline $3 / 4$ & 87 & 64.8 & 22.2 \\
\hline $5 / 6$ & 654.8 & 42 & 22.8 \\
\hline 7 & 42 & 16.5 & 25.5 \\
\hline
\end{tabular}




\subsection{Conclusion and Discussion}

In this chapter, EPA standard driving cycles were tested on our simulated vehicle model to indicate the average DOD and total discharging time in each scenario.

FTP-72 represents the urban driving route in a standard temperature and pressure. Results indicate the average DOD of $7 \%$ for each FTP-72 cycle and total discharging time of 200 minutes. This standard cycle has the highest discharging time and lowest average DOD compared to other EPA standards.

HWFET is the highway driving route simulation in a standard temperature and pressure. Results indicate the average DOD of $18.75 \%$ for each of the two HWFET cycles and total discharging time of 100 minutes. DOD in HWFET driving cycle is higher than FTP-72 due to the higher achieved speed on highways.

SC03 driving cycle represents the engine load and emission associated with the use of air conditioning in vehicles. Results indicate an average DOD of $11 \%$ for each SC03 cycle and total discharging time of 120 minutes. A/C usage of the vehicles increases DOD for this driving cycle compared to FTP-72. Moreover, the discharging time of SCO3 is 80 minutes less that FTP-72.

US06 developed to address the shortcoming with the FTP-72 test cycle in the representation of aggressive, rapid speed fluctuation and high acceleration driving behavior following vehicle startup. Results indicate an average DOD of $20 \%$ for each US06 cycle 
and total discharging time of 70 minutes. The highest DOD and lowest total discharging time belong to US06 in comparison with other EPA standards.

Therefore we can conclude that, aggressive driving and use of air conditioning affect DOD of PEVs' battery pack significantly. In general, PEV's driver behavior directly influences the recharging time. Table 3.5 summarizes captured results for all EPA standards.

Table 3.5: EPA tested driving cycles results.

\begin{tabular}{|c|c|c|}
\hline EPA standards & Average DOD in each cycle (\%) & Total discharging time (minutes) \\
\hline \hline FTP-72 & 7 & 200 \\
\hline HWFET & 18.75 & 100 \\
\hline SC03 & 11 & 120 \\
\hline US06 & 20 & 70 \\
\hline
\end{tabular}




\section{Chapter 4}

\section{PEV-Station Interaction and}

\section{Driving Algorithm}

In previous chapters, the discharging behavior of EV batteries were studied. Different driving cycles create different discharging rates. Therefore, PEVs charging needs in different times depends on their driving pattern. The goal of consumer is to charge their PEV fast while considering minimum overall waiting time in charging process. Charging PEVs takes a long time. Therefore, drivers have to consider the distance between possible stations for charging and the availability of stations. This chapter proposes a system that defines an interaction between stations and PEVs. 


\subsection{Queueing Model and Station Framework}

In general, charging process of PEVs in urban areas can be modeled with multiple charging stations with queue length $N$ [33]. Figure 4.1 represents multiple charging stations with a single queue structure. Let us denote a PEV charging event using Poisson process for each station. As interpreted from Figure 4.1, PEV's charging process is a queue system. A queuing system consists of one or more servers that provide charging services from the grid to arriving PEV consumers. Consumers who arrive to find all servers busy join one or more queues (lines) in front of the servers [33]. In this described framework, Poisson arrivals and exponential services enable us to use Markovian queuing models that are easy to analyze and produce usable results.

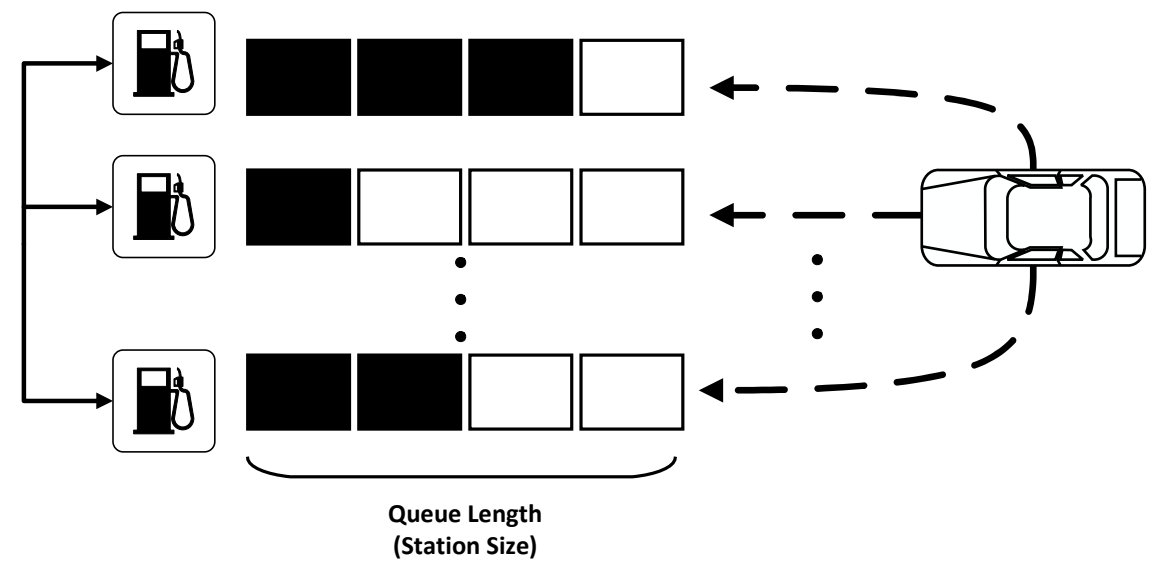

Figure 4.1: Multi-station framework with multiple $M / M / 1$ queue system [33]. 
Markov process is representing the number of customers in such system as a birth-anddeath process, which is widely used in population models [34]. Since charging stations represent a single queuing structure, studying $M / M / 1$ queueing system for this framework is required.

\subsubsection{M/M/1 Queueing Model}

The $M / M / 1$ queue is the simplest of the queuing models used in practice. First $M$ characterized the arrival. The arrivals are assumed to occur in a Poisson process with arrival rate of $\lambda$ per hour. This means, the number of customers $N(t)$ arriving during a time interval $(0, t]$ has a Poisson distribution [34]. Second $M$ characterized the services. The services are assumed to occur in exponential behavior with a rate of $\mu$ per hour. The third character indicates the number of servers which is one in this case. Generally, M\&M indicate the memory-less property of the arrival and services, or Markovian property of arrival and services [34]. Figure 4.2 shows the basic queuing analysis for PEVs. The system dictates that the average time that each car spends in the queuing system $(W)$ and the average number of people in the system $(L)$ have a proportional relationship. Average waiting time spent in the queuing system include average time each car spends in the server $\left(W_{s}\right)$ plus average time each car spends in the queue $\left(W_{q}\right)$. Moreover, average people in queue include average people in the server $\left(L_{s}\right)$ and queue $\left(L_{q}\right)$. The 
relationship between utilization quantity $(\rho), L_{s}$ and $L_{q}$ is stated in (4.1) [34]. $\rho$ is the fraction of time which is defined as ratio of arriving rate $\lambda$ and service rate $\mu$.

defines $W_{s}$ and $W_{q}$ by applying the Little's law [34].

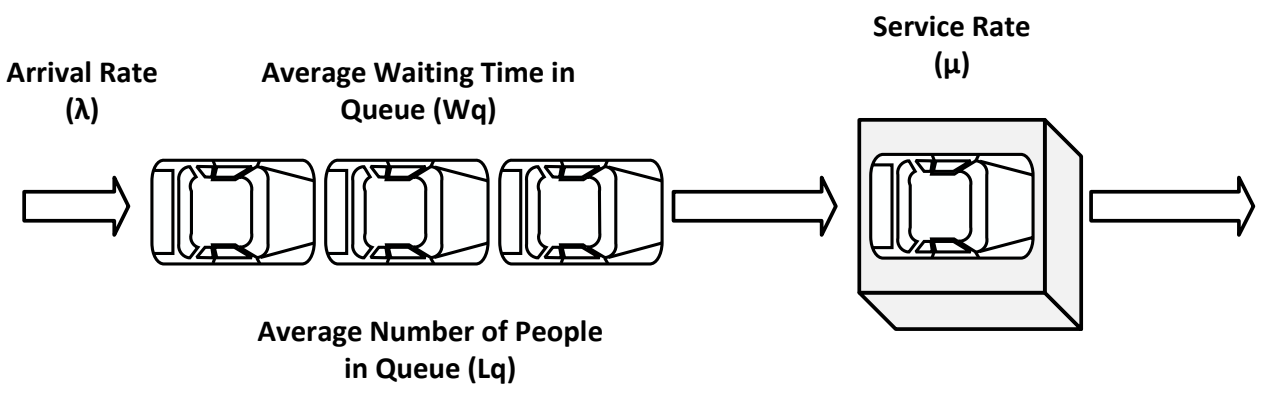

Figure 4.2: $M / M / 1$ queue structure and analysis.

$$
\left\{\begin{array}{l}
\rho=\lambda / \mu \\
L_{s}=\frac{(1-\rho) \rho}{(1-\rho)^{2}}=\frac{\rho}{1-\rho} \\
L_{q}=L_{s}-\frac{\lambda}{\mu}=\frac{\rho}{1-\rho}-\rho \\
L=L_{s}+L_{q}
\end{array}\right.
$$

By Little's law : $\left\{\begin{array}{l}W_{s}=\frac{L_{s}}{\lambda} \\ W_{q}=\frac{L_{q}}{\lambda} \\ W=W_{s}+W_{q}\end{array}\right.$ 
As it stated before, the PEV charging framework can be built considering the $M / M / 1$ queuing probability. From the stationary distribution of $M / M / 1$ queue, the mean queue size at each station is computed by (4.3) [33].

$$
E\left[N_{i}\right]=\frac{\mu_{i}}{\mu_{i}-\lambda_{i}} .
$$

The symbols $\lambda_{i}$ and $\mu_{i}$ denote arrival and service rates of PEVs for station $i$ per hour respectively. $E\left[N_{i}\right]$ represents the mean value of customers for station $i$.

\subsection{Modeling PEVs and Charging Stations}

Mapping the PEVs and charging stations is the next stage of this process. We modeled PEVs and charging stations on a 2-D system in Figure 4.3. Nine stations with equivalent distances are distributed in this platform. Initially, $100 \mathrm{PEVs}$ were tested on this platform considering $M / M / 1$ queueing model for existing stations. For this model, PEVs' initial SOCs and their locations are selected randomly. All the existing PEVs in the system started their operation in $\mathrm{CD}$ mode $($ Mode $=0)$. In this mode, the PEVs randomly move in their defined coordinates until their SOC reaches CS mode (mode $=1$ ).

For this simulation, since our framework aimed to cover the urban driving cycle, Figure 3.9(b) was used to show the discharging behavior of each PEVs over time. This discharging profile identifies when the PEVs need to recharge. PEVs reaches critical 


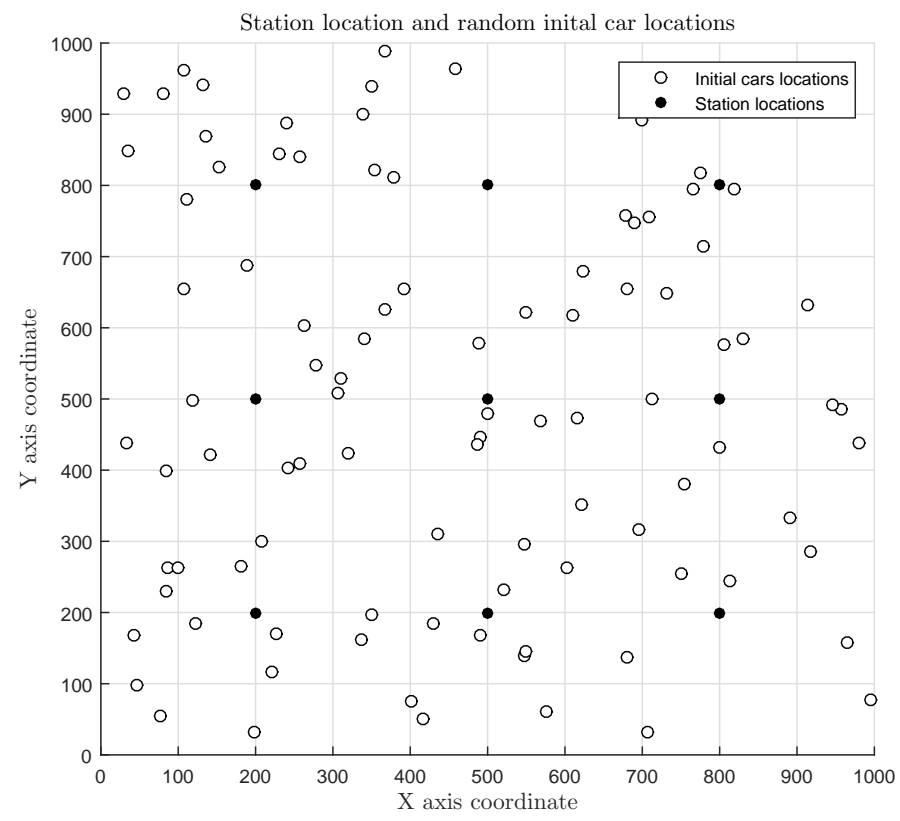

Figure 4.3: Proposed 2-D system with $x$ interval $[0,1000]$ and $y$ interval $[0,1000] .100$ PEVs and 9 stations are existed in this platform. PEVs initial location is selected randomly.

mode when the car SOC is $30 \%$. In critical mode (mode=1) PEVs need to recharge their battery. Therefore, they have to move towards a station. PEVs can find the optimum station by communicating with the data center. The data center can process all the input variables such as SOC, the distance of the vehicles to stations and the queue size of each station to suggest the best station to harmonize overall queuing size. Figure 4.4 presents the moving pattern of a PEV for a day (1440 minutes) and how data center suggests the best charging stations considering shortest path between the vehicle and stations. In Figure 4.4, solid line indicates mode 0 (CD mode), where PEV randomly moves until its SOC reaches $30 \%$. Upon reaching $30 \%$ of charge, PEV's mode changes to 1 until vehicle 


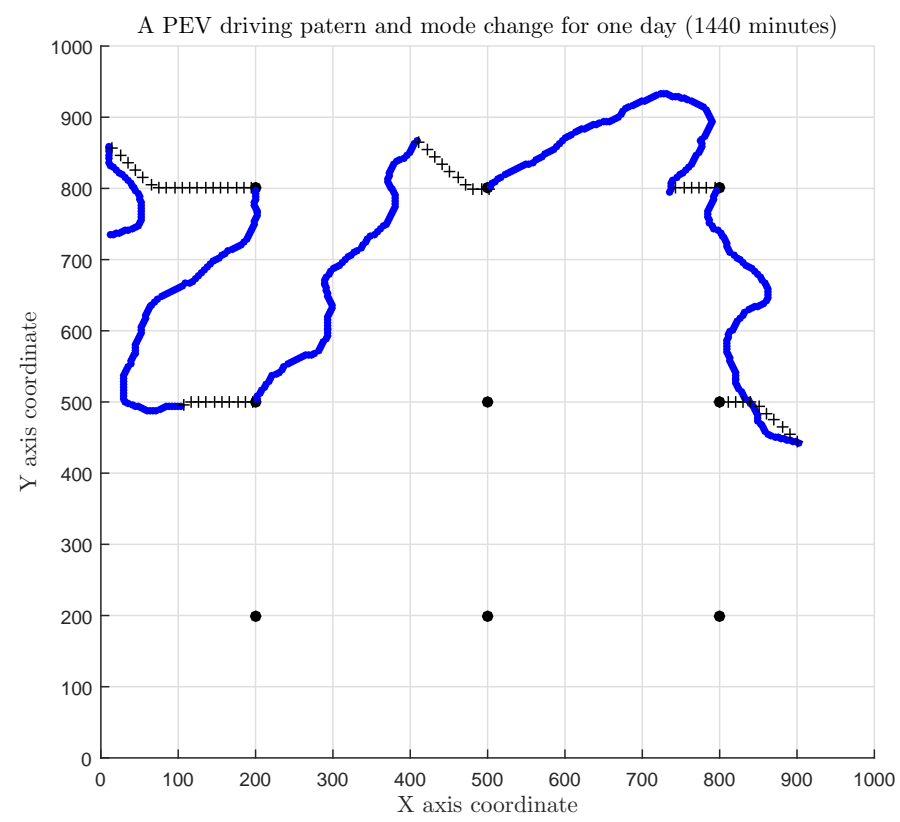

Figure 4.4: A PEV driving and mode pattern for one day. Charging station is selected based on closest distance between the PEV and stations. solid line(mode=0) indicates the driving pattern of the vehicle and plus sign indicates driving patern of the vehicle when SOC is critical (mode=1).

reaches to selected station. When the vehicle reaches the station, the queue size of the station is increased by one. Charging stations are assumed to possess superchargers.

Superchargers represent the most advanced charging technology in the world at this time presented by Tesla Motors. These chargers are 16 times faster than most public charging stations. Superchargers are capable of delivering up to $120 \mathrm{~kW}$, which can replenish half a charge in as little as 20 minutes and a full charge in 75 minutes [35]. Therefor, PEV spends 75 minutes to charge $($ mode $=2$ ) in each station. The mode changes back to zero when the PEV is charged to $98 \%$. Consequently, the PEV leaves the station, and the station's queue size is updated (decreased by 1). Figure 4.5 shows the flow chart 
algorithm for this procedure.

\subsection{Utility Function}

The objectives of this computer modeling are to balance the load of each charging station and minimize the overall waiting time for the customers. The data center can process and find the optimal station for PEVs considering distance and the queue size of each station. The function presented in (4.4) is proposed to make such a decision. $D_{i j}$ is

distance between station $i=\{1,2,3 \ldots . N\}$ and vehicle $j=\{1,2,3 \ldots . M\} . Q_{i j}$ denotes queue size of station $i$ when vehicle $j$ needs to be charged. $\mathrm{N}$ and $\mathrm{M}$ are set to 9 and 100 respectively. Coefficient 'a' defines consumer's sensitivity to the distance between vehicle and stations and coefficient 'b' defines consumer's sensitivity to queue size of stations. $\beta$ and $\alpha$ are data center sensitivity parameters for $D_{i j}$ and $Q_{i j}$. The data center selects a station that minimizes $Z_{i j}$ every time a vehicle needs recharging.

$$
Z_{i j}=a \cdot D_{i j}{ }^{\alpha}+b \cdot Q_{i j}{ }^{\beta}
$$




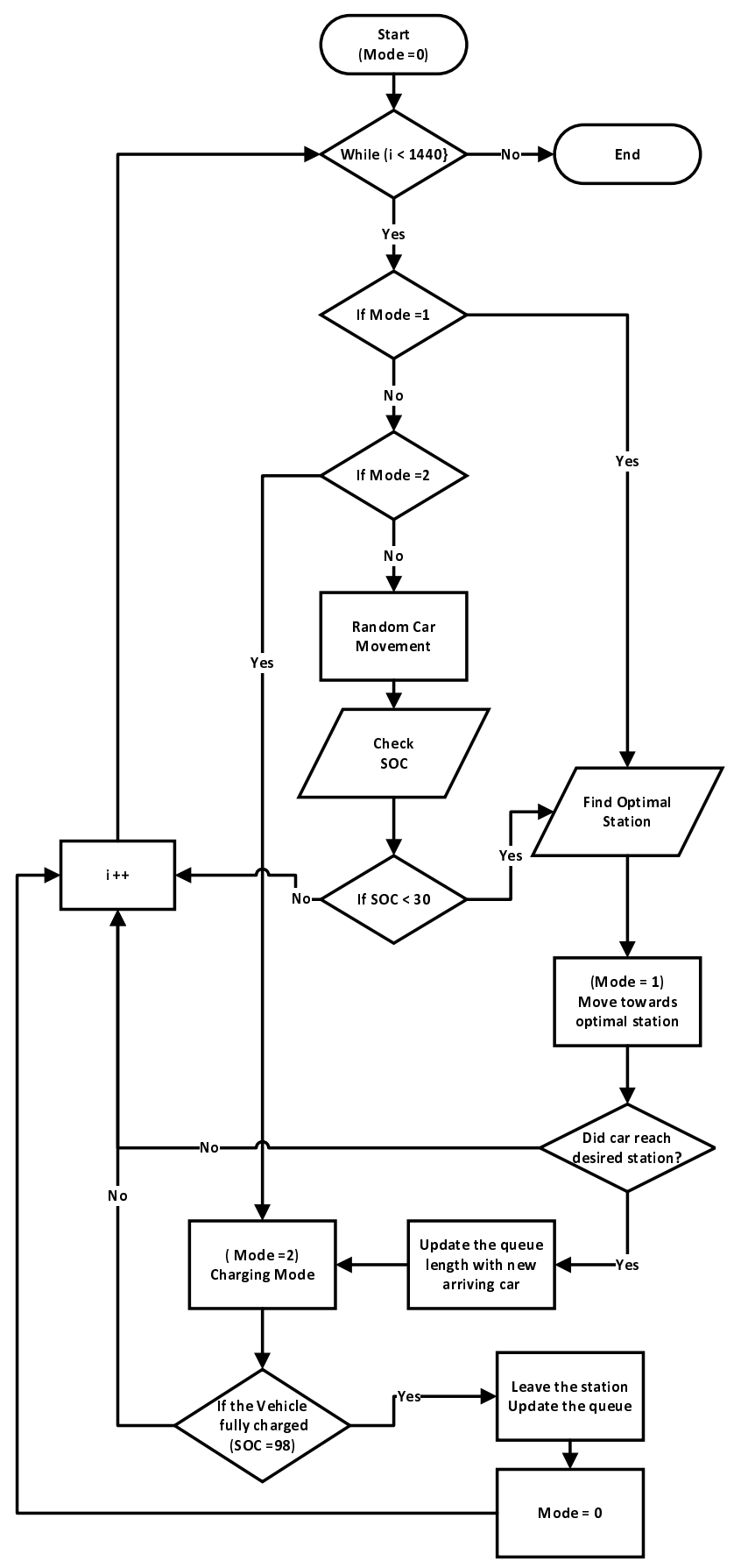

Figure 4.5: PHEV charging and driving flowchart algorithm in one day. 


\subsection{Selected Case Studies}

For understanding how each parameter affects overall stations' queue size, different case studies are required to test our parameterized equation in (4.4). Many different combinations of parameters and coefficients are applied to our decision equation to explore the impact of the data center to our proposed system. Following cases are the examples of our many tested cases in the interest of finding the most attainable solution.

Case I: Our first case focuses only on the shortest distance between vehicle and stations. From the drivers point of view, the first intention is to find the closest station to recharge their car. Therefore, our first case study is finding optimal station based on shortest distance only, and how this decision affects our charging stations' queue. Our parameters and coefficients are set accordingly in (4.4) where $\beta=0, b=0$, $a=1$, and $\alpha=1$.

Case II: Our second case focuses on the shortest distance between vehicle and stations while stations' queue sizes are taken into consideration as well. Since PEVs have a long recharging time, stations queue size is a significant factor. Besides driving a distance, drivers have to consider how busy each station is to minimize their overall recharging time. Therefore, finding optimal station based on shortest distance and queue size with equal priority is our second case study. Our parameters and coefficients are set accordingly in (4.4) where $\beta=1, b=1, a=1$, and $\alpha=1$. 
Case III: Our third case focuses on Higher priority to stations queue size in (4.4).

Besides minimizing the overall recharging time, harmonizing stations queue size helps us to provide better services to drivers. Therefore, finding optimal station based on shortest distance and queue size with higher priority may contribute to this goal. Our parameters and coefficients are set accordingly in (4.4) where $\beta=2$, $b=1, a=1$, and $\alpha=1$.

Table 4.1: Variability of each station queue size for each case study.

\begin{tabular}{|c|c|c|c|}
\hline Station Number & Case I & Case II & Case III \\
\hline \hline 1 & 5.93 & 3.17 & 2.95 \\
\hline 2 & 7.41 & 6.81 & 5.67 \\
\hline 3 & 4.27 & 5.87 & 3.52 \\
\hline 4 & 4.45 & 2.281 & 3.78 \\
\hline 5 & 3.52 & 18.74 & 3.12 \\
\hline 6 & 3.12 & 5.91 & 5.44 \\
\hline 7 & 11.78 & 2.92 & 3.87 \\
\hline 8 & 1.82 & 4.02 & 4.3 \\
\hline 9 & 5.56 & 4.45 & 3.89 \\
\hline
\end{tabular}

Table 4.2: Minimum variability of each station queue size in each case.

\begin{tabular}{|c|c|c|c|c|c|c|c|c|c|}
\hline Station number & 1 & 2 & 3 & 4 & 5 & 6 & 7 & 8 & 9 \\
\hline \hline Minimum variability & 2.95 & 5.67 & 3.52 & 2.28 & 3.12 & 3.12 & 2.916 & 1.82 & 3.89 \\
\hline Selected Case & 3 & 3 & 3 & 2 & 3 & 1 & 2 & 1 & 3 \\
\hline
\end{tabular}

Our model tested 100 PEVs for our proposed cases. PEVs' initial SOC and location is selected randomly. All vehicles were initially in CD mode and all simulations ran for 1440 minutes (a day). Our goal is to compare our cases and find minimum queue size 
variability. Table 4.1 summarizes the variability of each station's queue length in all 3 cases. The simulation was ran numerous times for higher level of accuracy. Statistical results show that Case 3 is better than Case 2 and 1 in terms of queue overflow. Case 2 was fairly better than Case 1 although not all the time. Table 4.2 indicates which case generates the minimum overall queue size variability in each station. Figure 4.6 demonstrates queue size behavior of all nine stations considering all three cases. 

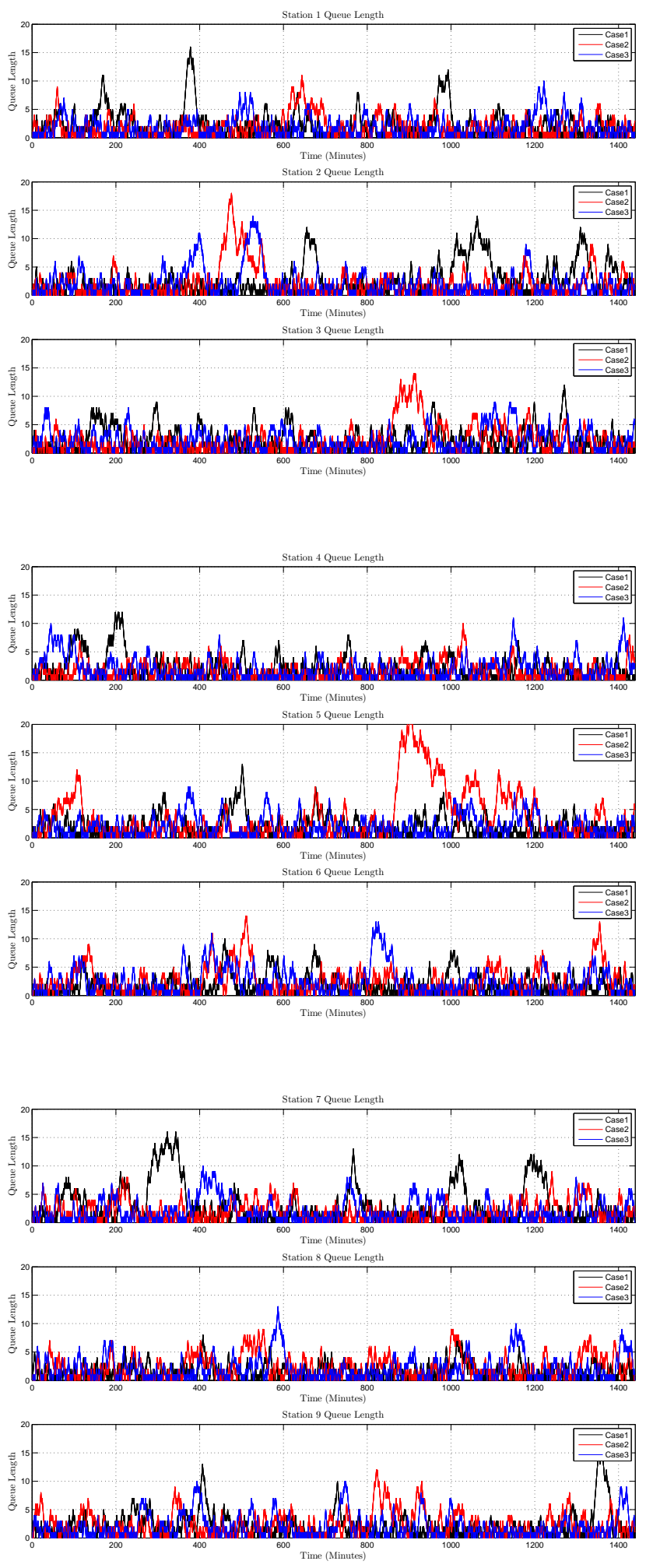

Figure 4.6: Queue size behavior of all 9 stations for all 3 tested cases. 


\section{Chapter 5}

\section{Practical Application and Analysis}

In previous chapters, a proper initial model was developed for PEVs considering different driving cycles and SOC. Also, a utility function was proposed for the data center to decide the optimum stations for PEVs to harmonize the overall load on queuing stations and minimize the overall waiting time of consumers. The randomness of driving pattern and distances plus the number of existing stations must be eliminated to develop an accurate model of PEVs charging process. Applying our proposed framework model in previous chapters to different cities eliminates random parameters and improves our decision function. Therefore, our suggested computer model was adapted to City of Toronto for further analysis in this chapter. 


\subsection{Mapping and Station Locations}

In the previous chapter, an initial platform was developed for the study of different PEV modes and behavior. However, a more realistic platform is necessary to improve the modeling of PEVs. A realistic city map helps to find the actual driving distance of PEVs to the location of existing charging stations.

\subsubsection{City of Toronto's Map}

Geospatial Map \& Data Center (GMDC) website provides access to geospatial datasets exclusive to Ryerson University [36]. Property Data Maps (PDMs), is the inventory for Toronto-centric data such as roads and building heights. CanMap Routelogistics, Census of Canada Profiles, and Digital Elevation Models are a few examples of accessible datasets via the GMDC Search [36]. Geospatial database for the City of Toronto includes various geospatial files including roads, clutter data, digital elevation, place names and building heights [37]. This data is usually used towards city planning, city modeling, traffic analysis and cultural and agricultural studies.

For this study, interest area is the downtown core of Toronto since most of the existing charging stations are located in this zone. Toronto geospatial data file converted to a MATLAB structure with a combination of provided MATLAB applications and functions such as image acquisition, image processing and computer vision. Downtown 


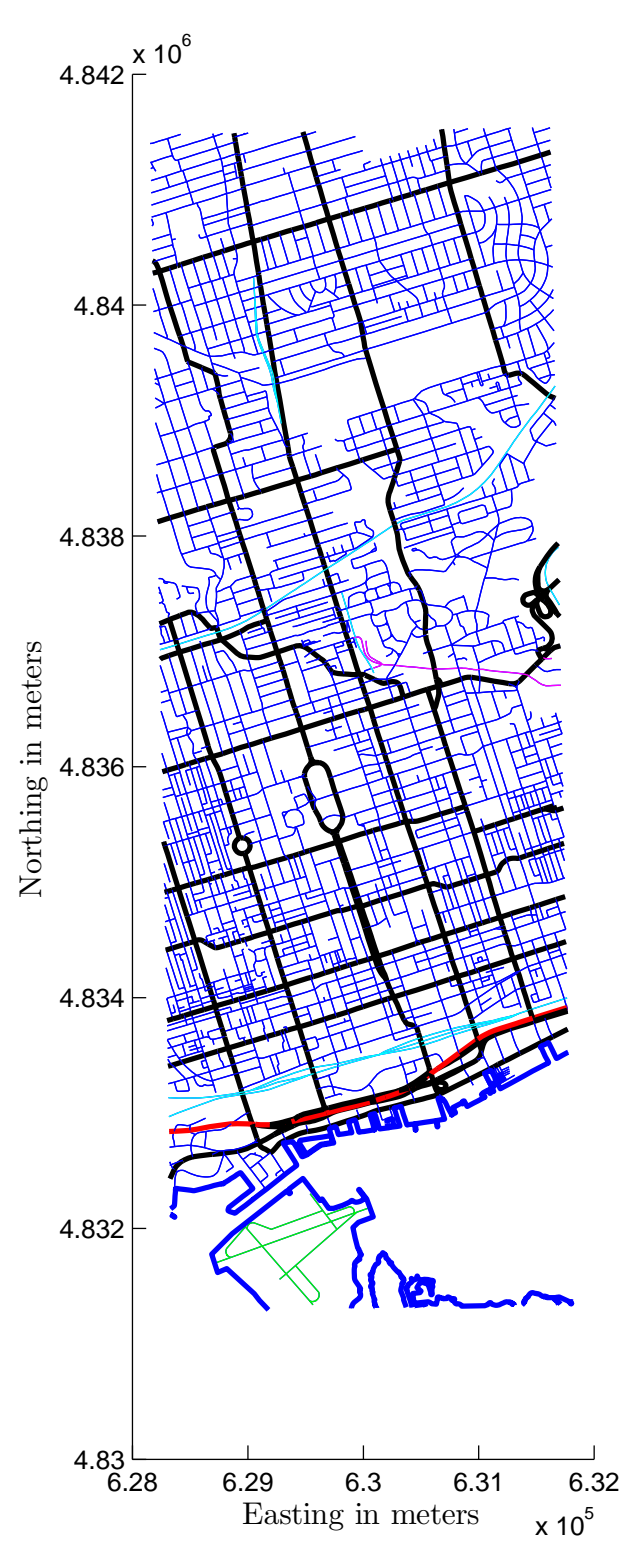

(a) Main roads are black, streets are blue, the highways are red, the railways are cyan, and airstrips are green. Lakes were defined with thicker blue lines.

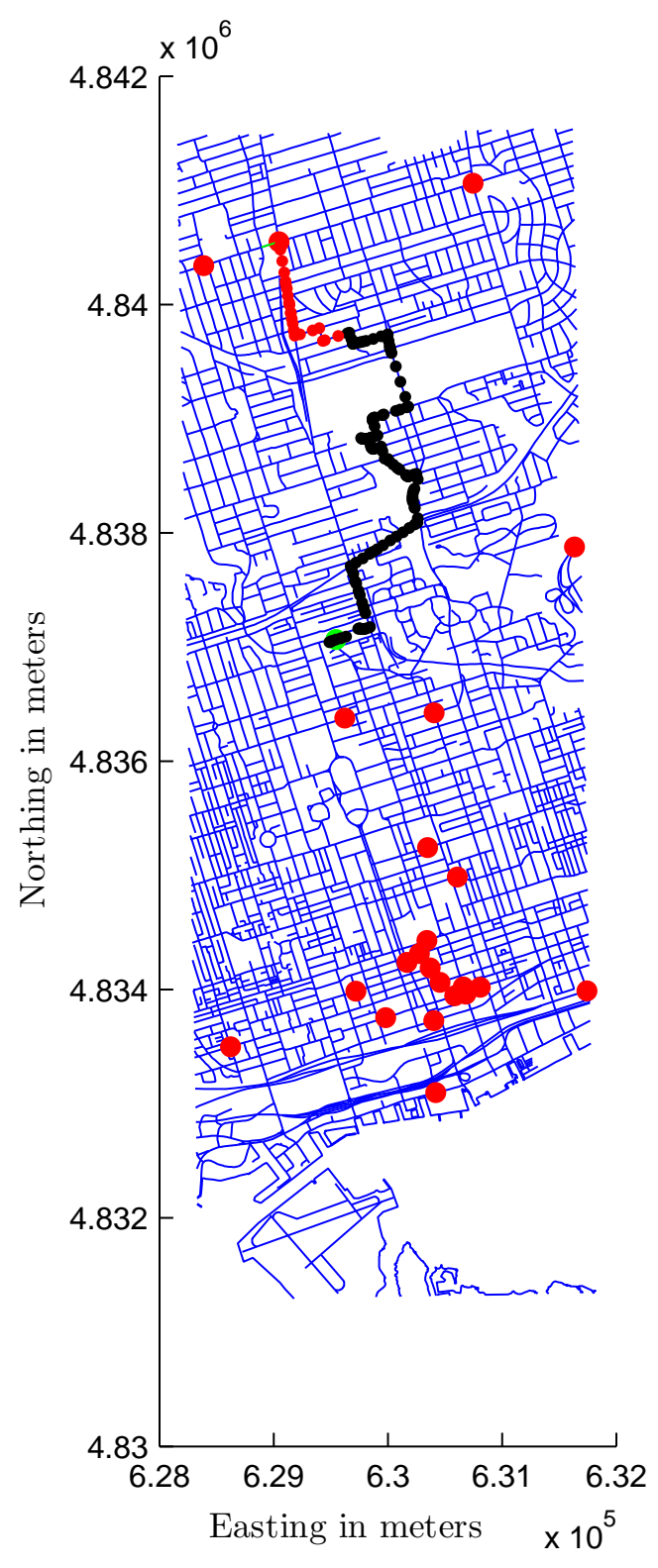

(b) Stations location in down-town Toronto. A PEV driving path to nearest charging station. PEV's CD mode and CS mode are indicated by black and red respectively.

Figure 5.1: Down town Toronto simulated map. 
Table 5.1: Grid and geographical area of selected downtown Toronto coordinates.

\begin{tabular}{|c|c|c|}
\hline Grid & Meters & Geographic \\
\hline \hline XMIN & 628,155 & W $79^{\circ} 24^{\prime} 41.628924^{\prime \prime}$ \\
\hline YMIN & 4831,275 & N $43^{\circ} 37^{\prime} 24.341916^{\prime \prime}$ \\
\hline XMAX & 631,815 & W $79^{\circ} 21^{\prime} 49.3506^{\prime \prime}$ \\
\hline YMAX & 4841,540 & N $43^{\circ} 42^{\prime} 54.640008^{\prime \prime}$ \\
\hline
\end{tabular}

Toronto includes highways, roads, main roads, airstrips and railways. Each structure is categorized separately in Figure 5.1(a). Table 5.1 summarizes the selected grid area in meters and geographical coordinates. A proper algorithm is applied to define each roads intersection and connections in a form of structure. Block roads were recognized for our algorithm efficiency.

\subsubsection{Modeling PEVs and Charging Stations in Toronto}

The selected area of downtown Toronto has 23 existing charging station. Figure 5.1(b) indicates the location of each charging station in our selected zone. Most of these stations are open 24 hours, seven days a week. 100 PEVs are being tested on this platform considering $M / M / 1$ queueing model for the stations. Toronto is a combination of highways, roads, and streets. FTP-72 discharging profile in 3.8(b) for Toronto urban driving, and HWFET discharging profile in 3.8(b) for Toronto highway driving were integrated to PEVs discharging rate.

Each PEV has random initial starting location and destination. Each vehicle finds 
the shortest possible path between the current location and final destination. A new destination will be assigned to each vehicle when they reached their destination. Our simulation ran for 1440 minutes (a day) for all 100 existing PEVs. For the recharging process, proposed algorithm in Figure 4.5 was adapted to analyze charging and driving procedures of each car. Figure 5.1(b) shows the movement of a vehicle to its closest station for recharge. Data center sends the vehicles to best possible charging station considering stations queue size and distance. For finding the best solution, (4.4) was normalized since each variable has a different unit. The normalized decision making equation represented in (5.1).

$$
f_{i j}(x, y)=a x_{i j}{ }^{\alpha}+b y_{i j}{ }^{\beta}
$$

where :

$$
\begin{array}{lr}
x_{i j}=\frac{D_{i j}}{D_{\max }} & y_{i j}=\frac{Q_{i j}}{Q_{\max }} \\
i=\{1,2,3 \ldots N\} & j=\{1,2,3 \ldots M\}
\end{array}
$$

Parameters $a, b, \alpha$ and $\beta$ are set to one for initial analysis of our computer model. Figure 5.2 indicates overall load on all 23 stations over one day. The overall load distribution illustrates that PEVs are distributed unevenly among existing stations. Figure 5.3 shows the kilometers driven in a day for all 100 PEVs. Each vehicle on average was driven 45.05 kilometers. 


\subsection{Sensitivity Analysis}

For limiting coordinated control on PEVs, the data center must have a minimum effect on selected optimum charging station. Therefore, the value of $\alpha$ and $\beta$ as sensitivity parameters for data center, are set to one in (5.1). The goal is to find the best value of 'a' and 'b' (customers sensitivity coefficients) to minimize $f_{i j}(x, y)$.

$$
\begin{array}{ll}
\underset{a, b}{\operatorname{minimize}} & f_{i j}(x, y)=a x_{i j}{ }^{1}+b y_{i j}{ }^{1} \\
\text { subject to } & x_{i j} \min <x_{i j}<x_{i j} \max \\
& y_{i j} \text { min }<y_{i j}<y_{i j} \text { max }
\end{array}
$$

Sensitivity analysis has several approaches depending on the complexity of a model. If a model is small enough to solve quite quickly, brute force method is usually applicable. However, if the model is enormous and takes a long time to solve, a formal method of classical sensitivity analysis is more reliable [38]. The brute force method rarely yields efficient algorithms, and it is not as constructive as some other techniques although it is wildly applicable and simple. Classical sensitivity analysis is tedious and is based on the relationship between the initial tableau and the optimum tableau. This analysis updates the optimum solution quickly when the coefficients of the original tableau change [38]. Computer-based ranging is a method between classical sensitivity analysis and brute force and aims for simple information about how much certain coefficients can change before 


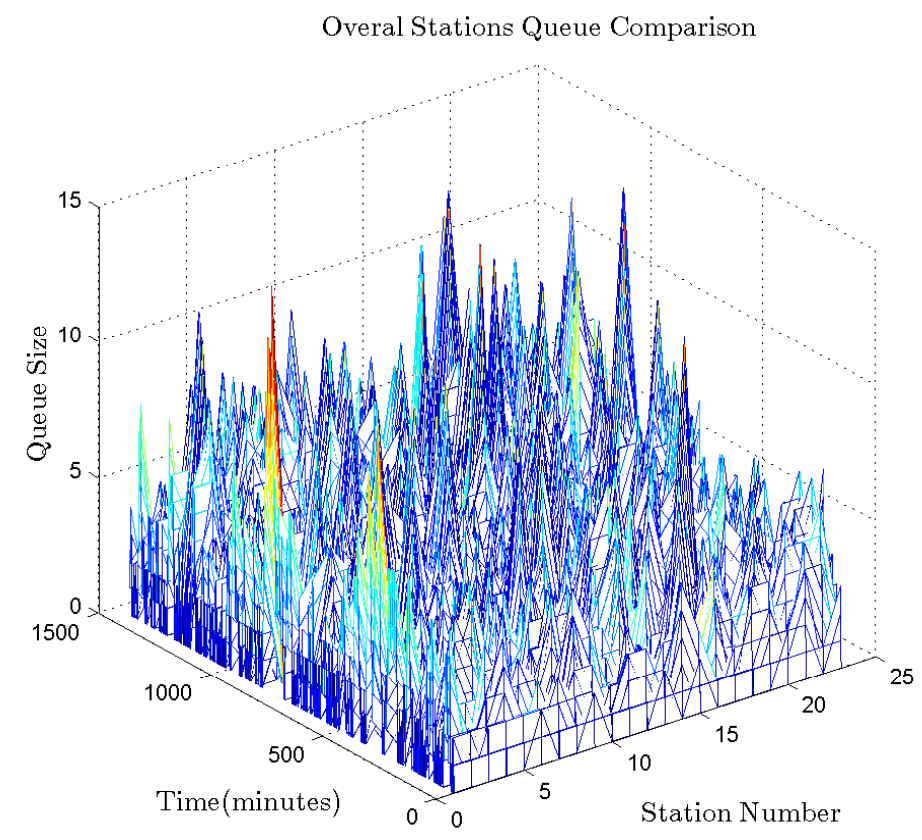

Figure 5.2: Overall load distribution of 23 charging stations queue in down-town Toronto for one day when all sensitivity parameters and coefficients are one.

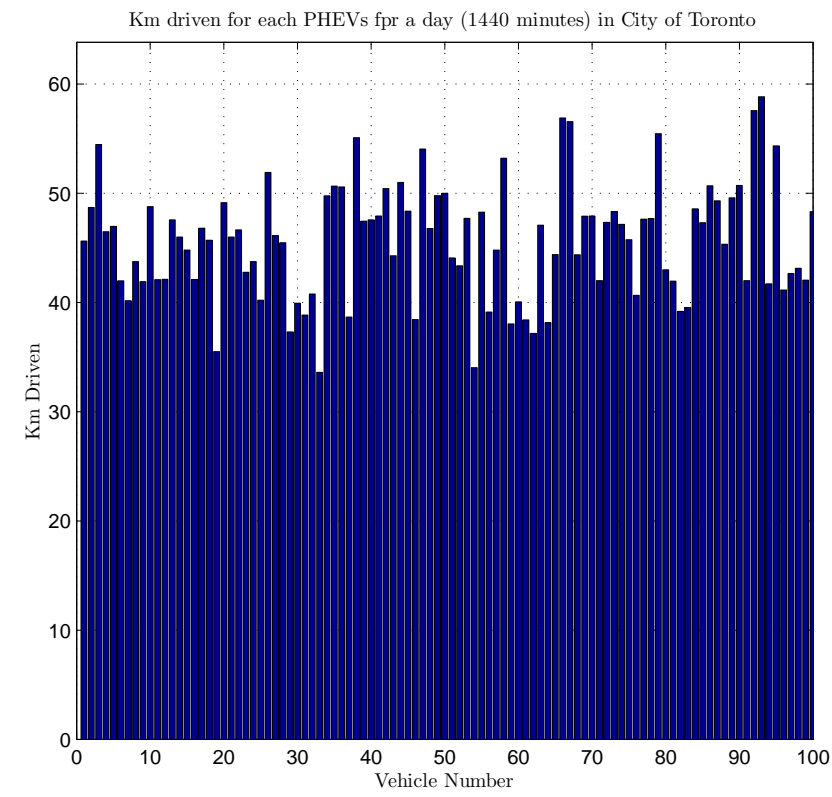

Figure 5.3: Km driven for all $100 \mathrm{PEVs}$ in down-town Toronto with average drive of $45.05 \mathrm{~km}$ for each vehicle when all sensitivity parameters and coefficients set to one(23 stations). 
significantly changing the outputs. It also determines the best combination of coefficients to optimize the desired function.

Since our function is a linear function, computer-based sensitivity analysis is ideal. Ordinal objective function coefficients ('a' and 'b') range from 1 to 5 . A bigger range for our sensitivity coefficients will compromise the balance of our function and reliability of each variable. Numerous iterations were simulated to find the best value of 'a' and 'b'. Results indicate that 1.25 and 1.75 are the best values for 'a' and 'b' respectively. These selected values can harmonize the overall load and minimize the queue size variability of stations. The Improved utility function based on sensitivity analysis is stated in (5.2). Figure 5.4 indicates the overall stations' queue load with the new optimum utility function. The overall queue load in Figure 5.4 is more harmonized in comparison with Figure 5.2. The average driven Kilometer is 48.22 according to Figure 5.5 which is not significantly higher from Figure 5.3.

$$
f_{i j}(x, y)=\frac{5}{4} x_{i j}+\frac{7}{4} y_{i j}
$$




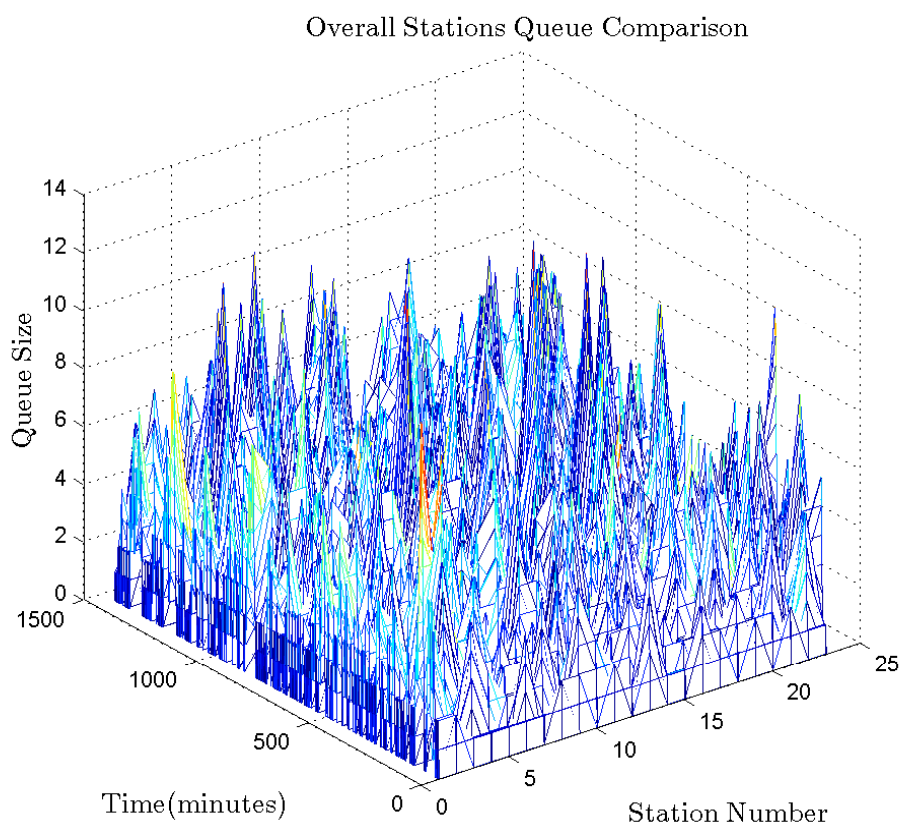

Figure 5.4: Overall load distribution of 23 charging stations queue in down-town Toronto for one day when all sensitivity coefficients was optimized.

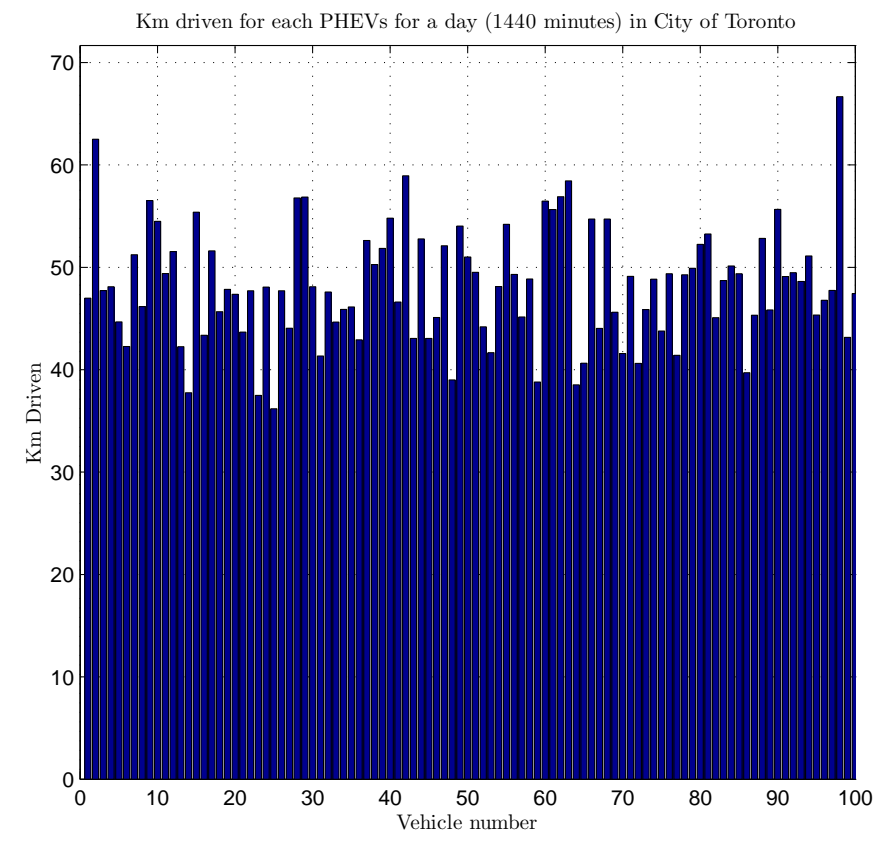

Figure 5.5: Km driven for all $100 \mathrm{PEVs}$ in down-town Toronto with average drive of $48.22 \mathrm{~km}$ for each vehicle when all sensitivity coefficients was optimized(23 stations). 


\subsection{Location Allocation}

An additional station can reduce the overall load to charging station and the overall

charging process. For locating a new facilities, many parameters should be taken into consideration. Factors that influence the facility decision are transportation, labor, material, equipment, land, market, energy, government, financial institutions, etc [39]. Since desired data is not available, this problem is limited to distance and accessible services to consumers. The distance between a new facility and existing facility is modeled in Euclidean distance [40]. Therefore, $d\left(x, y, c_{i}, d_{i}\right)$ is denoted as the distance between a new facility and existing facility $i$ in following equation:

$$
d\left(x, y, c_{i}, d_{i}\right)=\sqrt{\left(x-c_{i}\right)^{2}+\left(y-d_{i}\right)^{2}} .
$$

Our objective is to find $x$ and $y$ coordinates for a new facility that satisfy the following relation:

$$
\max f(x, y)=\sum_{i=1}^{m} w_{i} \sqrt{\left(x-c_{i}\right)^{2}+\left(y-d_{i}\right)^{2}} .
$$

Variables $x$ and $y$ are the location coordinates of the new station. $c$ and $d$ are location coordinates of existing station $i . w_{i}$ denotes weight associated with travel between the new station and existing station $i$.

Since there is no information associated with preferences and priorities of the new 


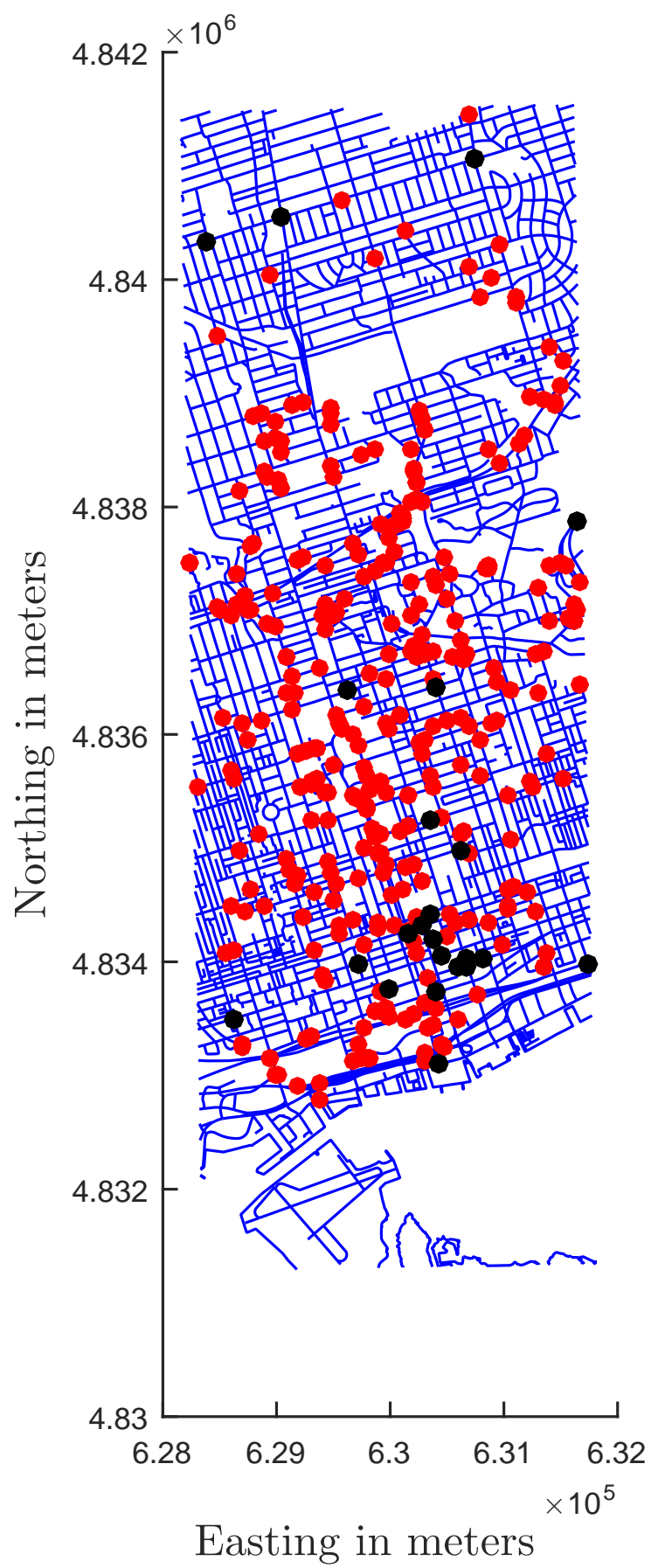

Figure 5.6: PEVs location of first critical SOC (red) and existing charging stations location (black) in downtown Toronto. 
station location, $w_{i}$ is set to one. Using (5.4) and (5.3), our first objective function is presented as followed:

$$
\max f(x, y)=\sum_{i=1}^{m} w_{i} \cdot d\left(x, y, c_{i}, d_{i}\right)
$$

where :

$$
w_{i}=1
$$

Figure 5.6 indicates the existing location of stations in downtown Toronto and location of PEVs first critical SOC. The locations indicate the first time vehicles communicate with the data center to find the best optimum station for recharging. The new station location also must have the closest distance to PEV's critical location. The distance between the new station and PEVs critical location also is defined with Euclidean models. Therefore, the relationship between location of PEV's critical SOC and a new facility is presented as followed:

$$
g(x, y)=\sum_{i=1}^{m} w_{i} \sqrt{\left(x-e_{i}\right)^{2}+\left(y-f_{i}\right)^{2}}
$$

Variables $x$ and $y$ are the location coordinates of the new station. $e$ and $f$ are location coordinates of existing station $i$. $w_{i}$ set to one. Considering (5.6), the distance between critical SOC and new station location must be minimized. Therefore, a second objective function is presented as followed: 


$$
\min \quad g(x, y)=\sum_{i=1}^{m} w_{i} \cdot d\left(x, y, e_{i}, f_{i}\right)
$$

where :

$$
\begin{array}{r}
d\left(x, y, e_{i}, f_{i}\right)=\sqrt{\left(x-e_{i}\right)^{2}+\left(y-f_{i}\right)^{2}} \\
w_{i}=1
\end{array}
$$

Figure 5.7 shows the applied combination of Minkowski and Chebyshev distance methods to find the best possible location for the new facility. First, Minkowski distance method was employed to indicate closest PEV's critical SOC locations into present station radius. Chebyshev distance method also is used to locate the maximum possible distance between existing station and the new station. Considering all the out of range PEV's critical SOC locations, new facility location is marked and indicated. The new location coordinate has the maximum possible distance to old stations and minimum possible distance to out of range PEV's critical SOC locations. 


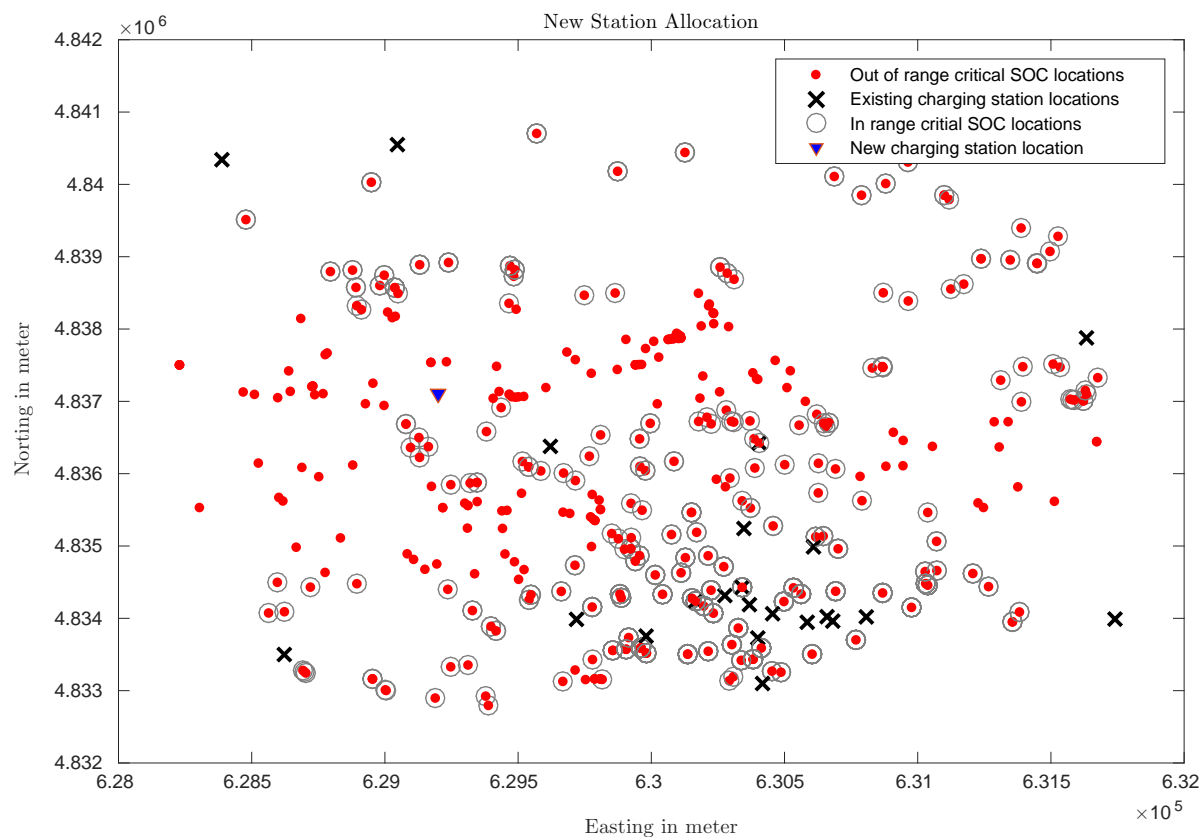

Figure 5.7: Applied Minkowoski and Chebyshev distance method results to allocate new facility location.

In Figure 5.8, additional new station to our desired model significantly reduces the overall load on charging queues. In fact, the overall queue load is decreased and distributed evenly among all 24 existing stations. The average driving is reduced to 42.03 Km for each vehicle compared to Figure 5.9. 


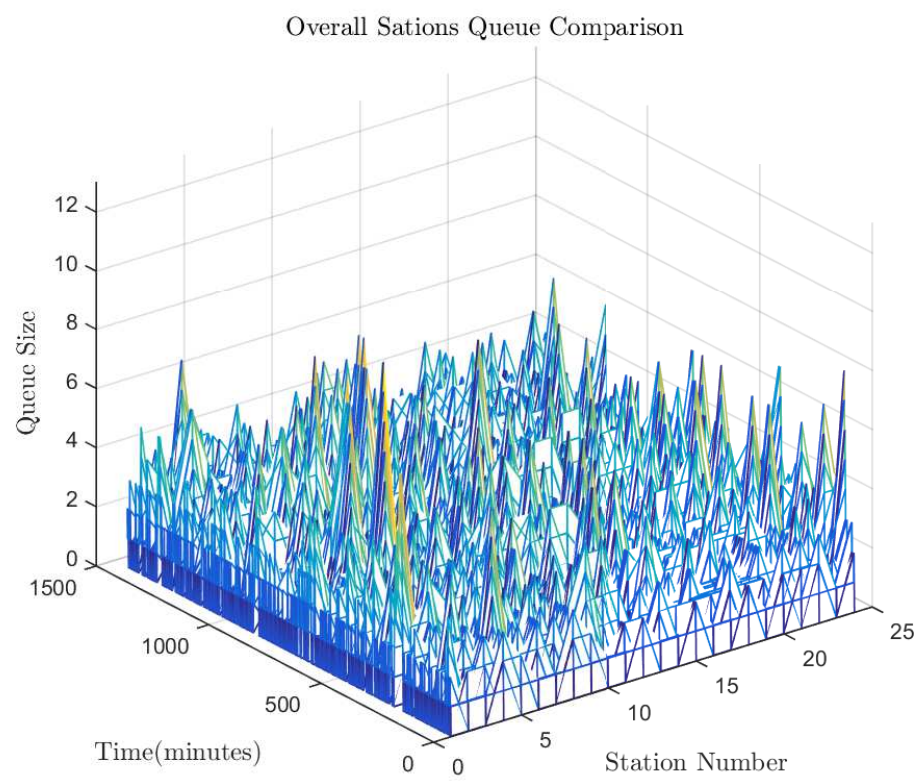

Figure 5.8: Overall load distribution of 24 charging stations queue in down-town Toronto for one day when all sensitivity coefficients was optimized.

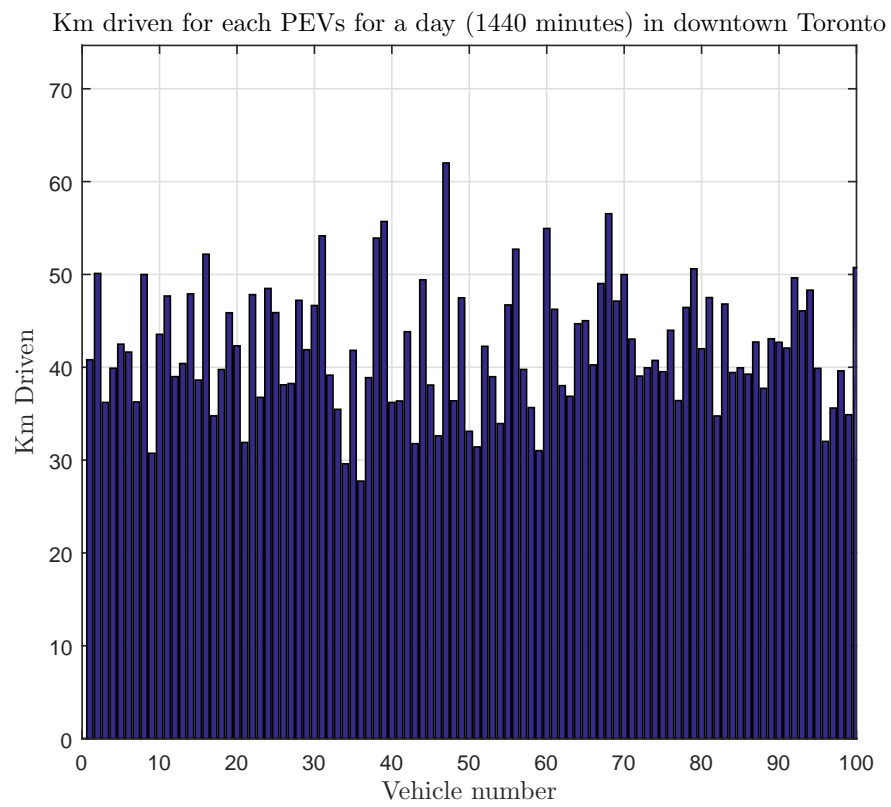

Figure 5.9: Km driven for all $100 \mathrm{PEVs}$ in down-town Toronto with average drive of $42.03 \mathrm{~km}$ for each vehicle when all sensitivity coefficients was optimized (24 stations). 


\section{Chapter 6}

\section{Conclusions and Future Work}

In this study, the State of Charge (SOC) discharging behavior was estimated using different existing driving cycle standards. PEV discharging rate is relevant to the speed of driving, the number of stops, acceleration and de-acceleration pattern of each vehicle. A

futuristic model was proposed for PEVs' driving pattern and charging and discharging behaviors. In the model, PEVs are assumed to be transmitting their SOC and locations in real-time. Data center finds the best charging station using our suggested utility function. The utility function considers stations' queue size and distance between the vehicle and stations. Moreover, downtown Toronto was simulated for a realistic study of PEVs' driving behavior.

As the result, proposed utility function was improved by sensitivity analysis. Furthermore, location allocation technique was applied for locating a new charging station. Location of PEVs first critical SOC and locations of existing stations are the primary inputs for locating our new facility. Results indicate new facility location will reduce the overall queue load and average driven distance. 
Seasonal and traffic conditions not only have a significant effect on the discharging rate of PEVs battery pack, but also affect the power grid performance. Power system peak hours and generated power are different in each season. Therefore, the power grid has some limitations to address drivers recharging needs. Moreover, accessibility of each station to other facilities such as movie theaters and coffee shops can improve the quality of services to consumers since the charging duration of PEV is long. Therefore, taking all the aforementioned factors into consideration for our decision making function will generate better results for PEVs drivers.

There are improvements that can enhance our results' accuracy. A survey of vehicle commuters in Toronto can help to improve the commuting distance statistics. The driving pattern study of Toronto drivers will generate a more accurate discharging profile of PEV's battery. Better estimation of the distance and timing of vehicle trips throughout a day would also improve the vehicle simulation portion of the model. An analytical analysis of service rate and arriving rate of PEVs in the city of Toronto would lead to a better and more realistic model. Statistical data such as transportation analysis, labor cost, equipment cost, land cost and market analysis would be a great help to improve the location allocation of a new charging station in the city of Toronto. Using rectilinear model instead of Euclidean model for defining the distance between the new station and existing stations, simplifies our proposed objective functions and avoids further complexity in our proposed framework. Rectilinear models represent the actual distances between new and existing facilities. Rectilinear model generates more realistic results although they are more difficult to solve because of multiple paths connecting any two points. 
Appendices 


\section{Appendix A}

\section{Parameters of Electric Vehicle}

\section{Model}

Below parameters were used in Figure 3.5 for our Similink model in chapter 3 :

\begin{tabular}{|c||c|}
\hline \multicolumn{1}{|c||}{ Vehicle Parameters } & Value \\
\hline Mass & $1200 \mathrm{Kg}$ \\
\hline Tire Radius & $0.3 \mathrm{~m}$ \\
\hline Wheel Inertia & $0.1 \mathrm{~kg} \cdot \mathrm{m}^{2}$ \\
\hline Aero Drag Coefficient & 0.26 \\
\hline Engine Vehicle Gear Ratio & 1.3 \\
\hline Distance CG Front Axle & $1.35 \mathrm{~m}$ \\
\hline Distance CG Rear Axle & $1.35 \mathrm{~m}$ \\
\hline Distance CG Ground & $0.5 \mathrm{~m}$ \\
\hline Tire Rated Vertical Load & $3000 \mathrm{~N}$ \\
\hline Tire Rated Peak Long Force & $3500 \mathrm{~N}$ \\
\hline Tire Slip At Peak Force & $6 \%$ \\
\hline Tire Relaxation Length & $0.25 \mathrm{~m}$ \\
\hline Trans Inertia & 0.5 \\
\hline Trans Friction & 0.0001 \\
\hline
\end{tabular}




\begin{tabular}{|c||c|}
\hline Internal Combustion Engine (ICE) Parameters & Value \\
\hline Shaft Inertia & 0.25 \\
\hline Max Power & $57000+57000 \mathrm{~W}$ \\
\hline Speed at Max Power & $5000 \mathrm{RPM}$ \\
\hline Max Speed & $6000 \mathrm{RPM}$ \\
\hline Friction & 0.2079 N.m.s $/ \mathrm{rad}$ \\
\hline Sensor Time constant & 0.005 \\
\hline
\end{tabular}

\begin{tabular}{|c||c|}
\hline Battery Model Parameters & Value \\
\hline Cell Nominal Cap & $50 \mathrm{Ah}$ \\
\hline Cell SOC initial & 0.9 \\
\hline Cell temperature initial & $25^{\circ}$ \\
\hline Cell thermal Capacitance & $400 \mathrm{~J} / \mathrm{C}^{\circ}$ \\
\hline Surface area of battery exposed to air & $0.01 \mathrm{~m}^{2}$ \\
\hline Convective heat transfer coefficient & $20 \mathrm{~W} / \mathrm{m}^{2} / \mathrm{K}$ \\
\hline Nominal Current Capacity & $15 \mathrm{~A}$ \\
\hline Electrolyte Freezing Temp & $-40 \mathrm{C}^{\circ}$ \\
\hline
\end{tabular}

\begin{tabular}{|c||c|}
\hline Controller Parameters & Value \\
\hline Engine Start RPM & $800 R P M$ \\
\hline Engine Stop RPM & $790 R P M$ \\
\hline Control Mode Logic TS & 0.1 \\
\hline Control ICE Kp & 0.02 \\
\hline Control ICE Ki & 0.01 \\
\hline Control Generator Kp & 10 \\
\hline Control Generator Ki & 3 \\
\hline Control Motor Kp & 500 \\
\hline Control Motor Ki & 300 \\
\hline Control Vehicle Speed Kp & 0.02 \\
\hline Control Vehicle Speed Ki & 0.04 \\
\hline
\end{tabular}




\begin{tabular}{|c||c|}
\hline DC-DC Convertor Parameters & Value \\
\hline Output Voltage & $500 \mathrm{~V}$ \\
\hline Resistance Losses & $0.625 \mathrm{Ohm}$ \\
\hline Control Kp & 0.01 \\
\hline Control Ki & 10 \\
\hline Minimum input Voltage & 20 \\
\hline Mean Boost Kp & 0.001 \\
\hline Mean Boost Ki & 1 \\
\hline Power to Heat ratio & $0.1 \mathrm{~W} / \mathrm{W}$ \\
\hline Thermal Mass & $0.1 \times 10 \mathrm{Kg}$ \\
\hline Specific Heat & $100 \mathrm{~J} / \mathrm{Kg} / \mathrm{K}$ \\
\hline Initial Temperature & $25^{\circ}$ \\
\hline Air Temperature & $298 \mathrm{~K}$ \\
\hline Convection Area & $20 \mathrm{~cm}^{2}$ \\
\hline Convection Heat Coefficient & $\left.100 \mathrm{~W} / \mathrm{m}^{2} \mathrm{~K}\right)$ \\
\hline
\end{tabular}

\begin{tabular}{|c||c|}
\hline Generator Parameters & Value \\
\hline Stator Resistance & 0.00475 Ohm \\
\hline Inductances $H$ & {$\left[\begin{array}{ll}0.000635 & 0.000635\end{array}\right]$} \\
\hline Torque Speed LUT Speed RPM & {$\left[\begin{array}{llll}0 & 120020003000400010000 & 15000\end{array}\right]$} \\
\hline Torque Speed LUT Torque N.m & {$\left[\begin{array}{lll}400400250150110 & 0 & 0\end{array}\right]$} \\
\hline Damping & $0.00001 \mathrm{N.m} /(\mathrm{rad} / \mathrm{s})$ \\
\hline Torque Control Time Constant & 0.04 \\
\hline Shaft Inertia & 0.2 \\
\hline Series Resistance & $0.01 \mathrm{Ohm}$ \\
\hline
\end{tabular}

\begin{tabular}{|c|c|}
\hline Motor Parameters & Value \\
\hline Stator Resistance & 0.091 Ohm \\
\hline Inductances $H$ & {$\left[\begin{array}{llll}0.001597972349731 & 0.002057052250467\end{array}\right]$} \\
\hline Torque Speed LUT Speed RPM & 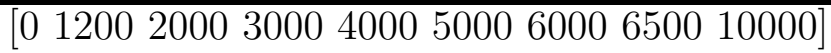 \\
\hline Torque Speed LUT Torque N.m & 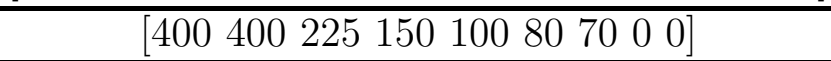 \\
\hline Damping & $0.00001 \mathrm{~N} . \mathrm{m} /(\mathrm{rad} / \mathrm{s})$ \\
\hline Torque Control Time Constant & 0.0267 \\
\hline Shaft Inertia & 0.2 \\
\hline$\overline{\text { Efficiency }}$ & $91 \%$ \\
\hline
\end{tabular}




\begin{tabular}{|c||c|}
\hline Ultra Capacitor Parameter & Value \\
\hline Nominal Capacitance & $1000 \mathrm{~F}$ \\
\hline Rated Cv & $0.2 \mathrm{Farad} /$ Volt \\
\hline Series Resistance & $15 \mathrm{Ohm}$ \\
\hline Initial Voltage & $217 \mathrm{~V}$ \\
\hline
\end{tabular}




\section{References}

[1] K. D. Lemoine, D. and A. Farrell, "An innovation and policy agenda for commercially competitive plug-in hybrid electric vehicles," Environ. Res. Lett., vol. 3, 2008.

[2] K. E. A. M. T. L. Duvall, M. and C. Clark, "Environmental assessment of plug-in hybrid electric vehicles.," Electric Power Research Institute, Palo Alto, CA, vol. 1, no. 1, 2001.

[3] W. Kempton and J. Tomic, "Vehicle-to-grid power fundamentals: Calculating capacity and net revenue," Journal of Power Sources, vol. 144, no. 1, pp. 805 -809, 2005.

[4] C. H. Stephan and J. Sullivan, "Environmental and energy implications of plug-in hybrid electric vehicles," Environ. Sci. Technol., vol. 42, no. 4, pp. 1185-1190, 2008.

[5] P. Denholm and W. Short, "An evaluation of utility system benefits of optimally dispatched plug-in hybrid electric vehicles.," National Renewable Energy Laboratory, 2006.

[6] A. Singhal and R. Saxena, "Software models for smart grid.," Software Engineering for the Smart Grid,International Workshop, vol. 455, no. 3, 2012.

[7] J. Tan and L. Wang, "Real-time coordinated management of phevs at residential level via mdps and game theory," in PES General Meeting - Conference Exposition, 2014 IEEE, pp. 1-5, July 2014. 
[8] W. Su and M.-Y. Chow, "Performance evaluation of an eda-based large-scale plugin hybrid electric vehicle charging algorithm," Smart Grid, IEEE Transactions on, vol. 3, pp. 308-315, March 2012.

[9] W. Shi and V. Wong, "Real-time vehicle-to-grid control algorithm under price uncertainty," in Smart Grid Communications (SmartGridComm), 2011 IEEE International Conference on, pp. 261-266, Oct 2011.

[10] T.-H. Chang, M. Alizadeh, and A. Scaglione, "Real-time power balancing via decentralized coordinated home energy scheduling," Smart Grid, IEEE Transactions on, vol. 4, pp. 1490-1504, Sept 2013.

[11] H. K. Nguyen and J. B. Song, "Optimal charging and discharging for multiple phevs with demand side management in vehicle-to-building," Communications and Networks, Journal of, vol. 14, pp. 662-671, Dec 2012.

[12] C. Wu, H. Mohsenian-Rad, and J. Huang, "Vehicle-to-aggregator interaction game," Smart Grid, IEEE Transactions on, vol. 3, pp. 434-442, March 2012.

[13] M. Weiss and D. Guinard, "Increasing energy awareness through web-enabled power outlets," in Proceedings of the 9th International Conference on Mobile and Ubiquitous Multimedia, p. 20, ACM, 2010.

[14] Y. Jeong and W. Kim, "A novel tpeg application for location based service using terrestrial-dmb," Consumer Electronics, IEEE Transactions on, vol. 52, pp. 281286, Feb 2006.

[15] "Universal battery parameterization to yield a non-linear equivalent circuit valid for battery simulation at arbitrary load.,"

[16] C. E. Inc, "Bu-402: What is c-rate," 2013. 
[17] K. Young, C. Wang, L. Y. Wang, and K. Strunz, "Electric vehicle battery technologies," in Electric Vehicle Integration into Modern Power Networks, pp. 15-56, Springer, 2013.

[18] M. Coleman, W. G. Hurley, and C. K. Lee, "An improved battery characterization method using a two-pulse load test," Energy Conversion, IEEE Transactions on, vol. 23, no. 2, pp. 708-713, 2008.

[19] Z. M. Salameh, M. Casacca, W. A. Lynch, et al., "A mathematical model for leadacid batteries," Energy Conversion, IEEE Transactions on, vol. 7, no. 1, pp. 93-98, 1992.

[20] V. Johnson, "Battery performance models in advisor," Journal of power sources, vol. 110, no. 2, pp. 321-329, 2002.

[21] D. Howell, "Annual progress report for energy storage r\&d, vehicle technologies program, energy efficiency and renewable energy," US Department of Energy, Washington, DC, 2010.

[22] D. Corrigan and A. Masias, "Batteries for electric and hybrid vehicles," Lindens handbook of batteries, 4th edn. McGraw Hill, New York, 2011.

[23] C. E. Inc, "BU-409 charging lithium-ion," 2013.

[24] B. A. Axsen, J. and K. S. Kurani, "Batteries for plug-in hybrid electric vehicles (phevs): goals and the state of technology circa 2008," Institute of Transportation Studies, 2008.

[25] G. Pistoia, Electric and hybrid vehicles: Power sources, models, sustainability, infrastructure and the market. Elsevier, 2010.

[26] M. Ehsani, Y. Gao, and J. Miller, "Hybrid electric vehicles: Architecture and motor drives," Proceedings of the IEEE, vol. 97, pp. 719-728, April 2007. 
[27] A. Emadi, Y. J. Lee, and K. Rajashekara, "Power electronics and motor drives in electric, hybrid electric, and plug-in hybrid electric vehicles," Industrial Electronics, IEEE Transactions on, vol. 55, pp. 2237-2245, June 2008.

[28] M. Cipek, D. Pavković, and J. Petrić, "A control-oriented simulation model of a power-split hybrid electric vehicle," Applied energy, vol. 101, pp. 121-133, 2013.

[29] T. Bougher, I. A. Khalek, S. Trevitz, and M. Akard, "Verification of a gaseous portable emissions measurement system with a laboratory system using the code of federal regulations part 1065," tech. rep., SAE Technical Paper, 2010.

[30] T. Canada, "Test Results Report - ford fiesta econetic," 2015.

[31] D. U.S. Government Printing Office, Washington, "Code of federal regulations," 2011.

[32] DieselBet, "Sftp-us06," 2013.

[33] D. Ban, G. Michailidis, and M. Devetsikiotis, "Demand response control for phev charging stations by dynamic price adjustments," in Innovative Smart Grid Technologies (ISGT), 2012 IEEE PES, pp. 1-8, Jan 2012.

[34] U. N. Bhat, An introduction to queueing theory: modeling and analysis in applications. Springer Science \& Business Media, 2008.

[35] T. Motors, "Supercharger the fastest charging station on the planet," 2015.

[36] R. University, "Geospatial map and data center," 2015.

[37] Ryerson University Open Source Geospatial Data, Geo-Database for Down Town Toronto. Geospatial Map and Data Centre, 2009.

[38] A. Levitin, Introduction to the Design 83 Analysis of Algorithms. Pearson, 2012. 
[39] E. M. Van Bueren and H. Priemus, "Institutional barriers to sustainable construction," Environment and Planning B, vol. 29, no. 1, pp. 75-86, 2002.

[40] Y. Bukchin and M. Tzur, "A new milp approach for the facility process-layout design problem with rectangular and l/t shape departments," International Journal of Production Research, vol. 52, no. 24, pp. 7339-7359, 2014. 